\title{
Nonlinear response of acid storage tank coupled with piping attachment under seismic load for optimal safe design
}

\author{
A. Jehanzeb Joyaa* (D), Mohamed J. Hyder ${ }^{b}$ (D), Yasir Zulfiqara (D) \\ ${ }^{a}$ Department of Mechanical Engineering, Pakistan Institute of Engineering and Applied Sciences, Islamabad, Pakistan. \\ Email: thejehanzeb@yahoo.com, aashi2014@gmail.com \\ ${ }^{b}$ Department of Mechanical Engineering, Capital University of Science and Technology, Islamabad, Pakistan. \\ Email: mjavedhyder1@gmail.com \\ * Corresponding author
}

https://doi.org/10.1590/1679-78256301

\begin{abstract}
Optimum safe design through numerically investigation and simulation of FSI due to seismic loading on acid tank with piping attachment is presented. A nonlinear FSI based on the FEM is performed on a full-scale 3D model. Investigations are supplemented by a CFD to simulate the fluid motion inside the tank using acceleration time history of Kocaeli earthquake, the response of the maximum stress, deformation, and displacement of rigidly restrained fixed and flexible tanks at different fill levels and thickness are evaluated. The results are compared and analyzed with design codes and the difference observed in hydrostatic pressure is less than $0.08 \%$, and in maximum values of hydrodynamic pressure are less than $4.3 \%, 0.8 \%$, and $1.5 \%$ at three fill level while the average difference in transient time history total pressure is less than $0.4 \%$. Finally, the provision given in the design codes and response of parameters is computed and polynomial correlation is proposed with an accuracy of above 0.99 and average difference less than $5 \%$ in fixed tank and less than $2 \%$ in the flexible tank for designing a safe tank by analysis.
\end{abstract}

\section{Keywords}

Hydrodynamics, FSI, CFD simulation, time history seismic analysis, sloshing, piping system

\section{Graphical Abstract}

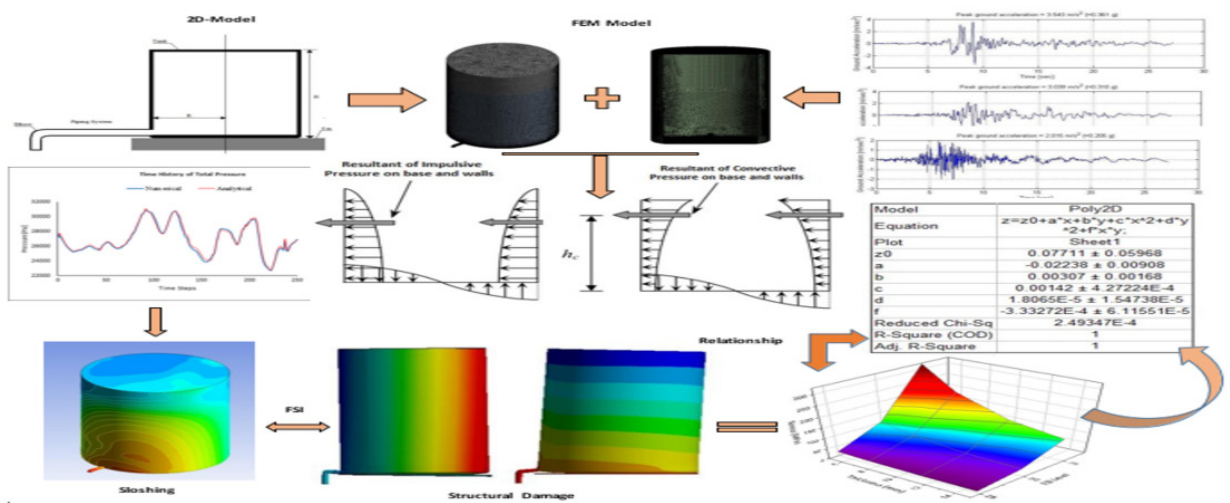




\section{INTRODUCTION}

Large fluid storage tanks with piping attachments are lifeline structures used in industrial and urban areas with a variety of applications ranging from water for drinking and firefighting, to store chemicals, petroleum, and LNG. In industries, tanks with piping attachments are a major source of transferring raw and refine fluid from a location to another. Not only failure during normal operations may cause serious accidents, but natural hazards such as earthquakes may cause extensive damage.

The seismic response of a liquid storage tank with piping attachments is quite different from conventional structures. In case of any damage or leakage of hazardous contents in form of toxic chemicals or fire pollution leading to unembellished significances to both atmosphere and human lives. Ultimately this damage to industrial facilities had a substantial impact on the economy in terms of both direct and indirect losses. Direct losses were a result of structural and nonstructural damage and indirect in terms of business and cost interruption (Sezen and Whittaker, 2004). The seismic loads lead to the breaking of contacts between pipes and equipment, due to the displacement of tanks connected with pipes that were detached, crushed, or bent. Resulting release and spilled of hazardous materials from several broken and damaged pipes, joints, and vessels (Krausmann, Cruz and Affeltranger, 2010)

Unlike the ductile building system, tank with piping attachment lack a mechanism to dissipate a large amount of seismic energy in a ductile manner(Malhotra, Wenk and Wieland, 2000), therefore earthquake damage can take several forms resulting in bending, buckling displacement, collapsing of tank, breakage or leakage of bolted flange connections between pipes(Bursi, Reza and Kumar, 2012)

Liquid sloshing (back and forth motions) in a partially filled tank establishes a broad class of problems of great practical importance concerning the safety of systems, such as industrial storage tanks under excited seismic ground motion, moving oil tankers on roads, dams, LNG ships. This fluid movement during sloshing creates highly localized impact pressure on tank walls which may, in turn, cause structural damage and may even create sufficient moment to affect the stability of the tank that may cause safety and optimal design issues, therefore sloshing in tanks is not a negligible phenomenon even at very small amplitude, the liquid movement during sloshing due to seismic excitations creates hydrodynamic pressure on tank and pipe walls(Eswaran and Saha, 2013; Zhao, M. \& Zhou, 2018)

Several investigations by researchers have been performed and methods for the seismic analysis are based on Housners studies(Housner, 1963) such as formulation method, boundary condition technique, and finite element method. However for general complex structure shape problems, the finite element method has advantages in solving, many of these studies focused on cylindrical and rectangular tanks at the ground level (Tehranizadeh, Amirmojahedi \& Moshref, 2016). S. Nicolici and R.M. Bilegan focused on the sloshing phenomena and the coupling computation fluid dynamic analysis with the finite element method(Nicolici and Bilegan, 2013).

Due to fluid-structure interaction, the nonlinear action of sloshing and its effect on the stability of the tank and its piping attachment is extremely complicated which leads to challenging design process(Çelik et al., 2018), Using ANSYS and MATLAB software numerical simulations, the dynamic behavior in a simplified 2-DOF FE model of a coupled tank piping system has been developed and investigated (Bursi et al., 2015)

Jhung, Myung Jo, and Ryu, Yong Ho developed a theoretical background for the time history analysis in ANSYS due to seismic excitation on the whole beam model with a base fixed acceleration time histories applied (Jhung and Ryu, 2010). Chen, Y. G., Djidjeli, K. Price, W. G. suggested a numerical approach for the seismic analysis of partially filled cylindrical tanks subjected to nonlinear hydrodynamic effects (Chen, Djidjeli and Price, 2009).

Fluid-structure interaction based on the Lagrangian approach was considered by Ghazvini, Taher Tavakoli, Hamid Reza Neya, Bahram Navayi Sarokolayi, Leyla Kalani for Numerical linear dynamic analysis of above ground tank considering earthquake accelerogram motions using finite element method, by assuming water as inviscid, irrotational, and homogenous with considering linear properties of tank material (Ghazvini et al., 2013).

D. Oliveira França Júniora, P. Ribeirob, and L. Pedrosoa presented a simplified solution using analytical methods of the finite element method for calculations free vibration and dynamic analysis through Ansys software of empty and filled tank having incompressible and inviscid fluid(De Oliveira França Júniora, Ribeirob and Pedrosoa, 2019). S. Cherif and M. Ouissi proposed a quadrilateral hierarchical finite element constructed from the shifted Legendre orthogonal polynomials for the free vibration analysis of a liquid in a rigid cylindrical tank considering with or without a free surface(Cherif and Ouissi, 2016).

For transient seismic analysis, many computer programs are available including ANSYS. Time histories are applied to the whole model and it is possible to include the acceleration time histories in the command, which defines degreeof-freedom (DOF) constraints at the level of the nodes. Now possible to apply all kinds of degree of freedom as a base excitation to specified nodes(Canonsburg, 2011; ANSYS Inc., 2013) 
This study focuses on the investigation of the piping system coupled with a standard acid storage tank designed as per standard codes. A nonlinear Fluid solid interaction approach has been followed by applying the distribution of hydrodynamic pressure due to sloshing. The acceleration time history of an earthquake is applied as a seismic dynamic load for coupling computational fluid dynamic CFD analysis with a finite element model of a piping system coupled with a tank that is developed in an ANSYS workbench environment. To understand the realistic behavior of the system an incremental nonlinear analysis is conducted and dynamic response on the pipe and tank is presented under the various fluid levels and different wall thicknesses. Finally, the applicability and methodology of the analysis type for optimal safe design by analysis are recommended for finding the nonlinear dynamic response due to seismic loads for piping attachments coupled with acid storage tank.

\section{FEM MODEL}

\subsection{Piping system coupled with tank model diagram}

A 2D model diagram of the piping system connected at the discharge point of the acid tank supported at the ground is shown in Figure 1.

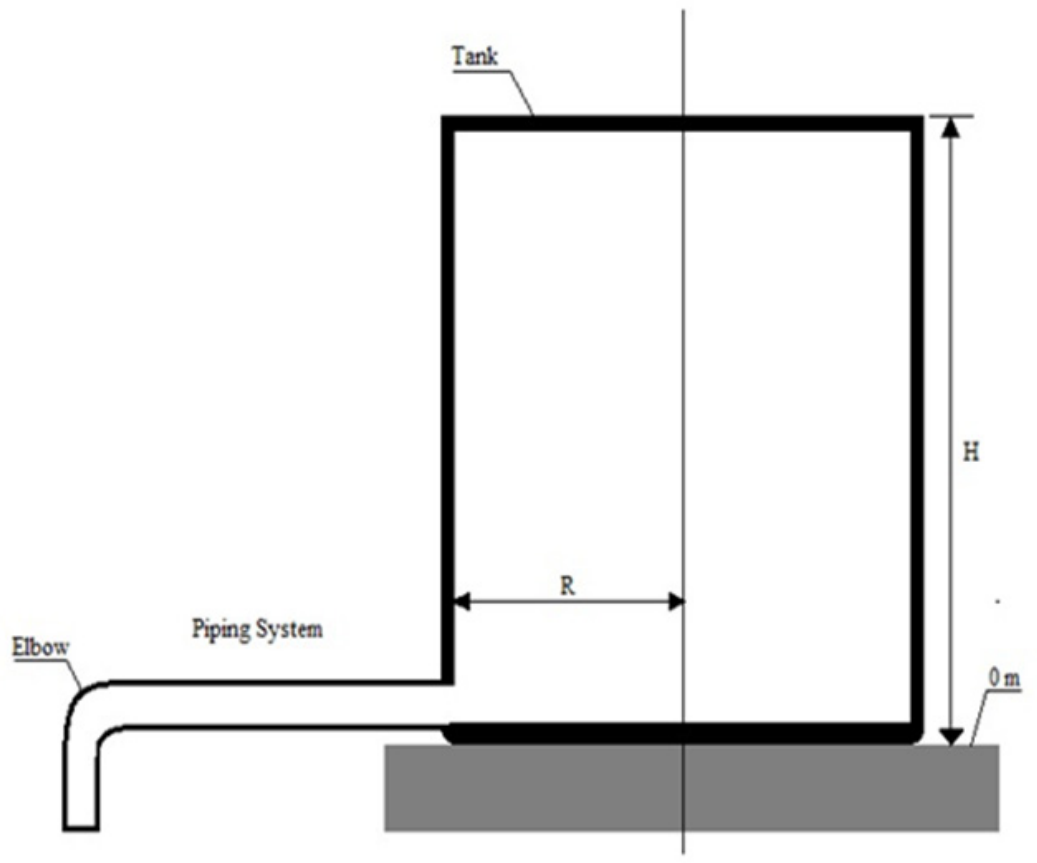

Figure 1 The piping system coupled with the tank.

\subsection{Specification of standard tank description}

The 9652.8 liters polyethylene upright acid storage tank is considered for analysis having an integrated molded outlet of $76.2 \mathrm{~mm}$, the tank inner diameter is 2.159 meter and height is 3.1496 meter, the tank has been designed using the relevant standards (D1998 - 15 ASTM 2015), top and bottom head are integrally molded with the cylindrical wall, the required minimum thickness of top head equal to the thickness of straight shell walls, it is difficult to control the absolute radius dimension in FEA or scientific analysis for a tank diameter greater than 1.8 meters, recommended that the outside radius of the bottom knuckle of a flat bottom be $38.1 \mathrm{~mm}$. Wall thickness varies from tank to tank based on the chemical being stored, operating temperature, and tank dimension. A fraction of an inch can make the difference between the tank that lasts for decades and one fails early. The wall thickness of the cylinder shell at any fluid level is determined by the following Equations,

$H L=H M-F$

Where, $\mathrm{HL}=$ head at level $\mathrm{F}, \mathrm{HM}=$ maximum fluid head and $\mathrm{F}=$ any fluid level. 
Wall thickness is given by,

$T=\frac{P x O D}{2 S D}$

$T=\frac{0.433 \times S G \times H \times O D}{2 S D}$

Where $\mathrm{P}$ is pressure, OD the outside diameter of the tank, SD hydrostatic design stress, SG specific gravity of fluid, and H fluid head.

To find the safe wall thickness of the tank which won't cause any structural damage varying wall thickness are used for analysis at different fluid levels starting from $5 \mathrm{~mm}$ to $\mathrm{max} 14.8 \mathrm{~mm}$ as calculated by the above equations.

\subsection{Piping system description}

The material used for the piping system for analysis is chemical compatible and resistant, and compliance with standards (B-16.5 ASME 2003) for border chemical resistance are considered. Scheduled 40 PVC material for down and straight pipes of $76.2 \mathrm{~mm}$ nominal diameter along with elbow are utilized in the piping attachment.

\subsection{CFD Model Description}

For this analysis, fluid is $\mathrm{HCl}$ in an acid storage tank of the following properties, Molar mass $=36.37 \mathrm{~g} / \mathrm{mol}$, Density $=1200 \mathrm{~kg} / \mathrm{m}^{3}$, and Dynamic viscosity $=0.0023$ Pas, for safe and reliable design of wall thickness, the effect of height to diameter ratio at the different fluid level inside the tank is described in Table 1 . These values have been deployed to model for the sloshing dynamics through ANSYS CFX code(Canonsburg, 2011).

Table $1 \mathrm{H} / \mathrm{D}$ ratios at the different fluid fill level

\begin{tabular}{ccccc}
\hline \multicolumn{3}{c}{ Height to Diameter Ratios } \\
\hline Fill Level & $1 / 4$ & $2 / 4$ & $3 / 4$ & $4 / 4$ \\
H/D & 0.3647 & 0.73 & 1.094 & 1.45 \\
\hline
\end{tabular}

Considering the effect of gravity by applying the buoyant model with the portion above fluid is air having reference pressure of $1 \mathrm{~atm}$ using a standard multiphase free surface homogeneous model, to simulate free surface, the system of model equations is supplemented with the equation of transfer of the fill function $F$ that expresses "concentration of liquid in gas" (when considering gas-liquid flow). This implies the name of the model of the flow Volume Of Fluid (VOF) model (Kochevsky, 2004). This allows the simulation of a two-phase flow of liquid and gas represented by Equation (4).

$$
\frac{\partial(F \rho)}{\partial(t)}+\frac{\partial}{\partial x_{j}}\left(F \rho u_{j}\right)=0
$$

where $\rho$ is the density of each phase, and $u_{j}$ is velocity projection to the axis $x_{j}$. On the index $j$, F equals 1 in the volume occupied by fluid and 0 in the volume occupied by gas. Only for cells crossed by the free surface, $0<F<1$. The initial position of the free surface should be specified by defining fluid height in each case.

Sloshing dynamics are turbulent flow, assuming fluid incompressible and inviscid, not considering the viscous effect near-wall by using free slip condition. The volume of fluid along with the $k-\epsilon$ turbulence model is used to compute the sloshing behavior of the fluid (Nicolici and Bilegan, 2013; Tahmasebi, Shamsoddini and Abolpour, 2020), Reynolds Equation (5) describing a turbulent model.

$$
\frac{\partial}{\partial t}\left(\rho \bar{u}_{i}\right)+\frac{\partial}{\partial x_{j}}\left(\rho \overline{u_{i} u_{j}}\right)+\frac{\partial}{\partial x_{j}}\left(\overline{u_{i} \dot{u}_{j}}\right)=-\frac{\partial p}{\partial x_{i}}+\frac{\partial}{\partial x_{j}}\left[\mu\left(\frac{\partial \overline{u_{i}}}{\partial x_{j}}+\frac{\partial \overline{u_{j}}}{\partial x_{i}}\right)\right]+f_{i}
$$


Where $\bar{u}$ represent time averaged velocity components, ú fluctuating velocity components, $\mu$ effective viscosity, $\rho$ density, and $f_{i}$ is the user defined momentum source. Second order backward Euler transient scheme formulation is applied as an implicit method to solve the hydrodynamic equations at any given time step.

\subsection{Fluid Mesh and Grid Convergence}

Computational mesh in fluid structure interaction (FSI) Problem has been split into fluid and structure mesh. For better accuracy of numerical results and capture of the free surface, mesh size is important in CFD calculations. For acceptable Mesh size before calculations several convergence analyses are performed to achieve mesh independence at different fill levels on mesh size ranging from $140 \mathrm{~mm}, 120 \mathrm{~mm}, 100 \mathrm{~mm}, 80 \mathrm{~mm}$, and $60 \mathrm{~mm}$, based on the results using linear element order of uniform mesh size $80 \mathrm{~mm}$ is chosen to the whole multi-phase considering free slip wall of the tank in CFD (Nicolici and Bilegan, 2013) and is shown in Figure 2, well converged the residual values at all the time steps in CFD, closed to numerical and analytical results in which percentage error is less than $5 \%$ and the CFD solution imbalances are less than 1\%. Further satisfying the statistical quality from other grid sizes satisfying the CFD mesh statistics of Orthogonal angle, Expansion Factor, and Aspect Ratio as described in Table 2.
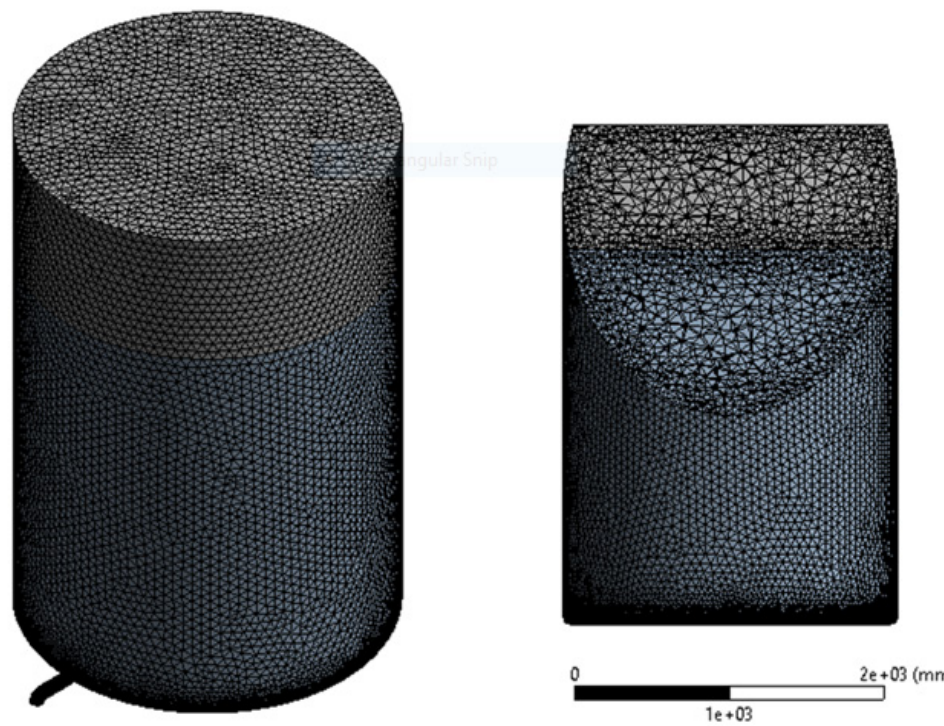

Figure 2 Fluid domain mesh with an inside view

Table 2 Fluid Mesh Statistics

\begin{tabular}{cccc}
\hline & Mesh Size 80 mm & \\
\hline Fill Level & $25 \%$ & $50 \%$ & $75 \%$ \\
Element quality & 0.83509 & 0.8349 & 0.83465 \\
Aspect Ratio & 18.567 & 18.577 & 18.587 \\
Skewness & 0.12069 & 0.23178 & 0.23188 \\
Orthogonal angle & 48.2 & 46.5 & 46.9 \\
Expansion factor & 11 & 17 & 12 \\
Nodes & 51365 & 51381 & 51207 \\
Elements & 260979 & 261243 & 260346 \\
Diverged Steps & 0 & 0 & 0 \\
\hline
\end{tabular}

\subsection{Structure Mesh and Grid Convergence}

The structure of piping attached to the tank is considered as 3D-solid elements. Mesh size convergence analyses are performed at the different thickness of shell and wall of the pipe and based on these results structure with mixed sizes and conformed mesh, the tank has meshed with $80 \mathrm{~mm}$ while piping system meshes size of $4 \mathrm{~mm}$, with face refinement for more accuracy at knuckle radius and tank discharge point as shown in Figure 3, well satisfying the mechanical mesh statistics having good element quality and skewness value as described in Table 3 , to achieve grid convergence. 

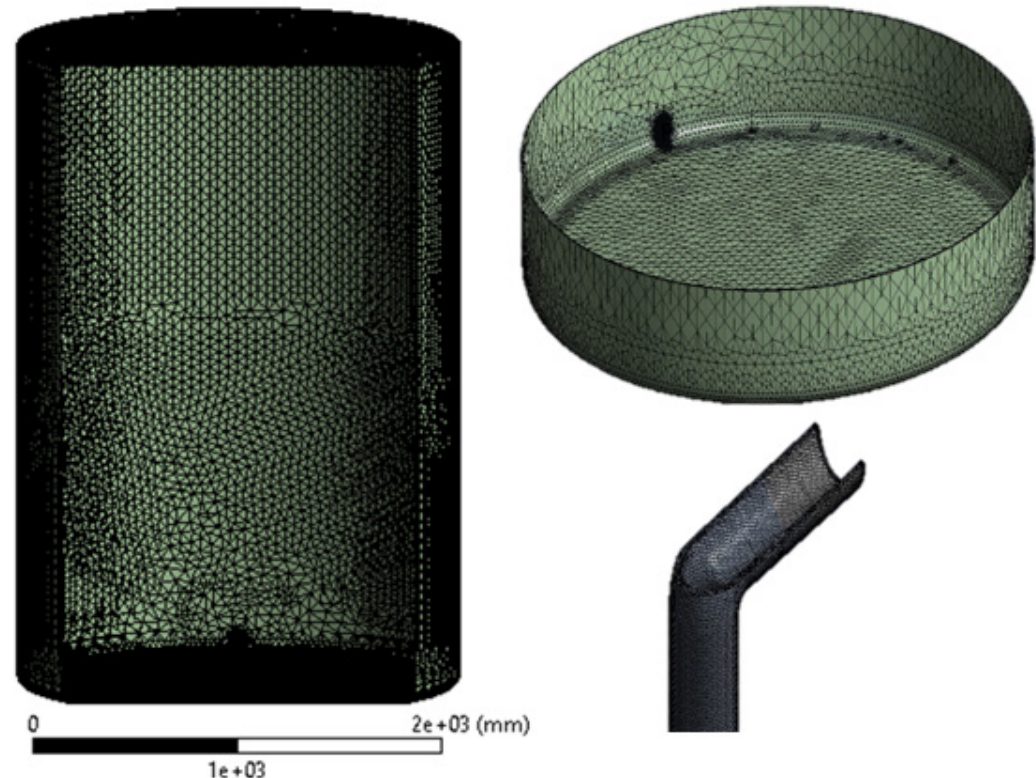

Figure 3 Structure mesh with an inside cross-section of tank and pipe

Table 3 Structure Mesh Statistics

\begin{tabular}{|c|c|c|c|c|}
\hline \multicolumn{5}{|c|}{ Grid Size 80 mm } \\
\hline Shell thickness & $5 \mathrm{~mm}$ & $7.4 \mathrm{~mm}$ & $11.1 \mathrm{~mm}$ & $14.8 \mathrm{~mm}$ \\
\hline Element quality & 0.579 & 0.62488 & 0.71473 & 0.76087 \\
\hline Aspect Ratio & 60.935 & 38.895 & 26.731 & 22.662 \\
\hline Skewness & 0.513 & 0.47608 & 0.3801 & 0.32678 \\
\hline Orthogonal angle & 0.48596 & 0.52188 & 0.6178 & 0.67109 \\
\hline Nodes & 416621 & 441782 & 587003 & 708647 \\
\hline Elements & 237847 & 258959 & 366143 & 455286 \\
\hline
\end{tabular}

\subsection{Seismic Input Modelling}

For investigating, the more realistic effect of the fluid solid interaction effect of piping coupled with acid storage tank under earthquake load acceleration time history is performed (Surh et al., 2015), time history analysis provides generally whole response of the system and give results of stresses that contain inertial and movement effects which can be utilized for safe design. For transient time history analysis Kocaeli earthquake having a magnitude of 7.4 is applied (Sezen and Whittaker, 2004), about forty percent of heavy industry in Turkey was concentrated in this region affected by this earthquake. The input acceleration time history response spectrum of the Kocaeli earthquake is shown in Figure 4, acceleration inputs for horizontal seismic load in the east-west with a peak ground acceleration (PGA)of $0.361 \mathrm{~g}$, south-north with a peak ground acceleration (PGA) of $0.310 \mathrm{~g}$, and in vertical peak ground acceleration (PGA) of $0.205 \mathrm{~g}$ are used. 


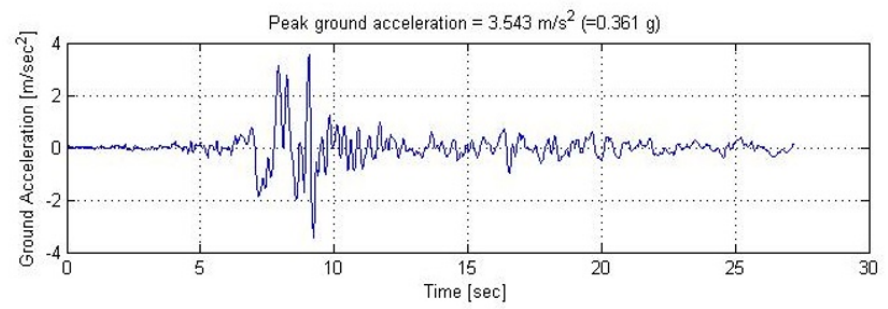

(a) Ground acceleration east-west component

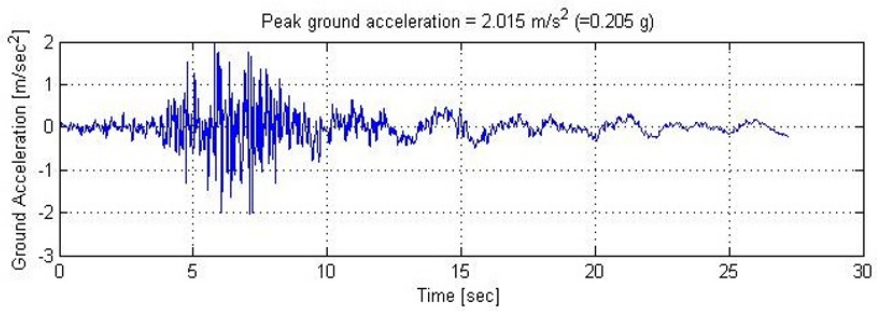

(b) Ground acceleration vertical component

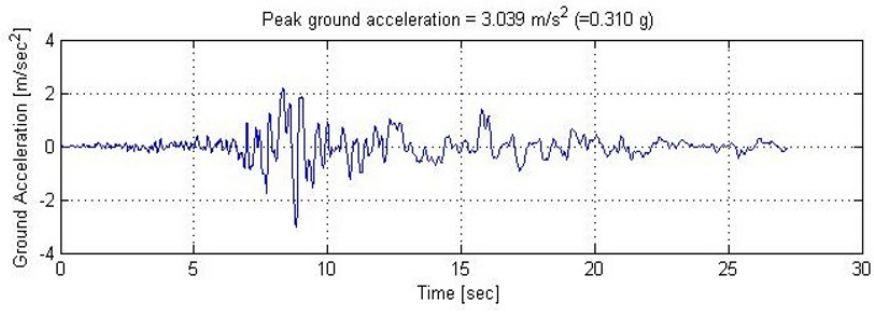

(c) Ground acceleration south-north component

Figure 4 Input ground acceleration time history components

Time dependent momentum source of seismic action on the fluid is given by Equation (6) considering structural domain fixed.

$f_{i}=\rho a(t)$

Where $f_{i}$ is the user defined momentum source, $\rho$ fluid density, and $a(t)$ express acceleration time record.

To avoid an unstable solution which results in the model to blow up, the time integrator required proper time for interpreting what is physically happening, for this Several sensitivity studies of acceleration time history analysis are performed to determine the time step applied in the computation, for stability and converged solution for a computational grid cell in a given time step. Time integrators concept by Courant number is given by Equation (7) which is a measure of information that traverses a computational grid cell in a given time step.

$C=u \Delta t / \Delta x(7)$

where $\Delta t$ is the time step, $\Delta x$ is the spacing of the grid in the numerical model, and $u$ the characteristic wave speed of the system. Therefore, to avoid any errors in the results, small time steps are used to achieve realistic results.

\subsection{Non-Linear Structural Finite Element Analysis}

The tank is considered anchored (fixed) and unanchored (flexible) at the base with piping attachment, the hydrodynamic pressure on the tank and piping walls are obtained during CFD simulation, results are coupled with a mechanical solver for FE analysis. A series of time varying nonlinear incremental analysis in details are conducted in two steps, Nonlinear behavior of structure depends upon large deflection of system, contacts (i.e base with the ground) and material nonlinearities, Simulation of the structural behavior of the tank and piping system are analyzed by the distribution of hydrodynamic pressure due to sloshing. Fluid structure interaction FSI dynamics of the structural part is represented in Equation (8). 
$M(\ddot{u})+C(\dot{u})+K(u)=F=-M \ddot{u_{g}}(t)$

where $\mathrm{M}$ mass matrix, $\mathrm{C}$ damping matrix, $\mathrm{K}$ stiffness matrix, and $\mathrm{F}$ are load vectors due to acceleration time history. Also $\ddot{u}, \dot{u}$ and $u$ are vectors of acceleration, velocity, and displacement of the structure respectively.

\section{COMPARISON FSI MODEL WITH DESIGN CODES}

\subsection{Hydrostatic Pressure}

Before seismic load, ground acceleration effects are not considered in the fluid. The pressure of the fluid is directly proportional to the fill height $h$, the density of the fluid $\rho$ and the gravitational field $g$, regardless of mass, surface area, or the geometry of structure it can be expressed in Equation (9) as follow,

$P=\rho g h(9)$

The hydrostatic pressure in the tank exerted by the fluid as shown in Figure 5 , is compared with the analytical values and the difference observed is less than $0.08 \%$ in three fluid fill level cases i.e $25 \%, 50 \%$, and $75 \%$. Figure 6 represents the comparison of analytical and numerical hydrostatic pressure before seismic excitation.
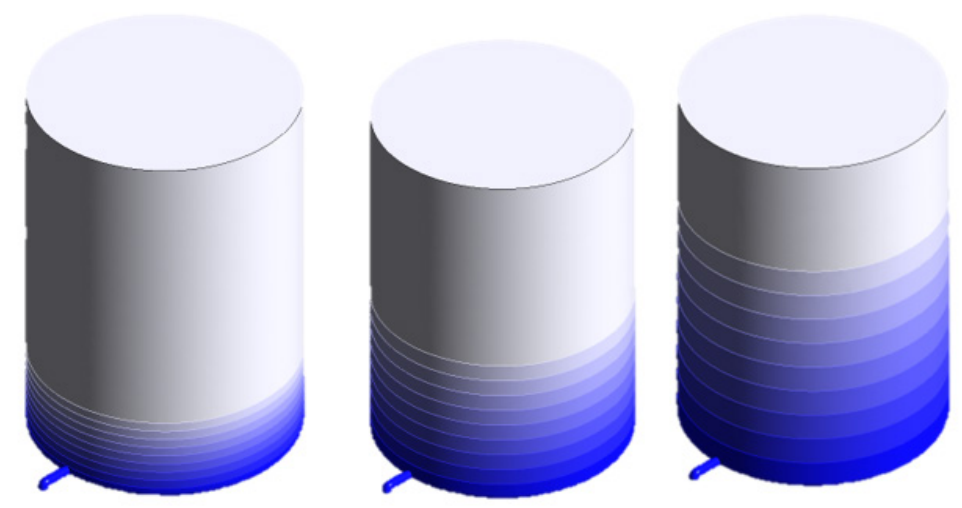

Figure 5 Hydrostatic Pressure distribution

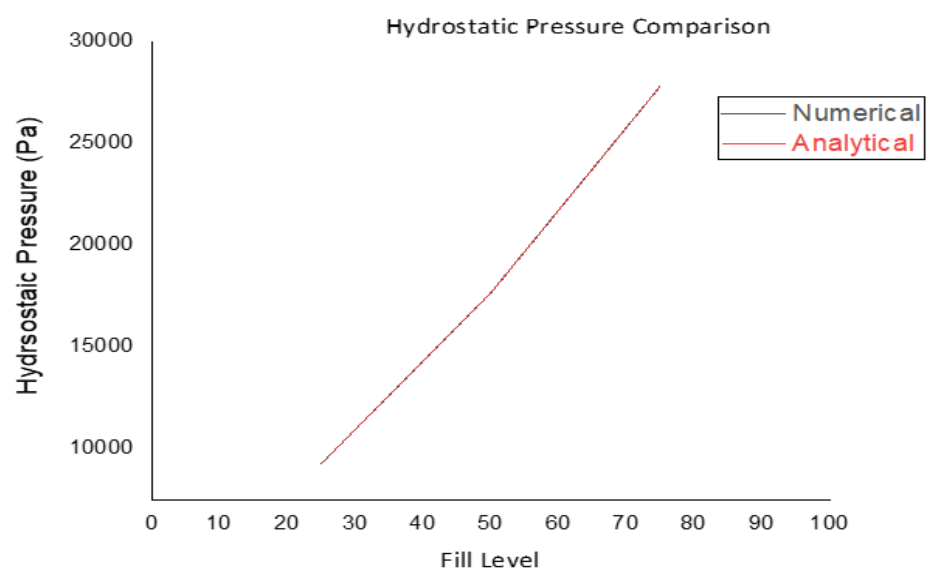

Figure 6 Comparison of hydrostatic pressure 


\subsection{Hydrodynamic Pressure}

Hydrodynamic pressure is caused by the sloshing effect generated due to the application of the seismic load as mentioned earlier. The total hydrodynamic pressure is represented by two components impulsive and convective (Euro code 8.4 2011). The lower part of the fluid acts like a mass that is firmly coupled to the tank walls. This mass is known as an impulsive mass that accelerates along with the wall and brings impulsive hydrodynamic pressure on the walls and correspondingly on the base, in the upper part, the fluid mass endures sloshing motion known as convective mass and applies convective hydrodynamic pressure on the base and walls.

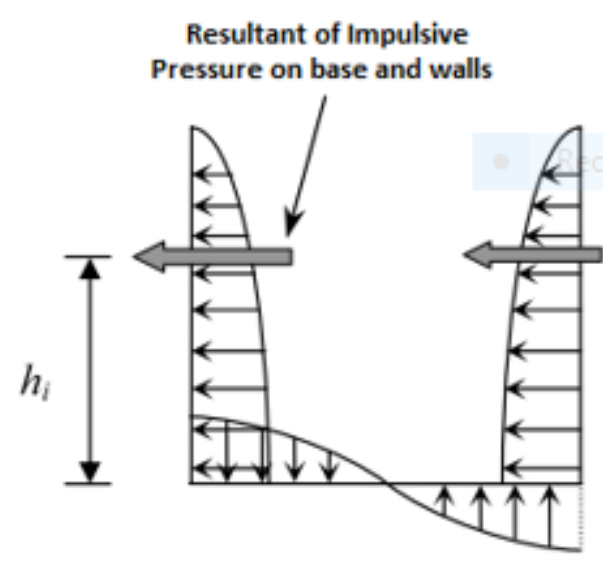

(a) Impulsive pressure on wall and base

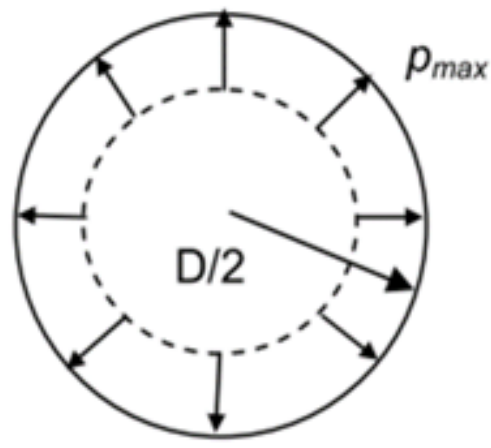

(C) Pressure distribution in circumferential direction

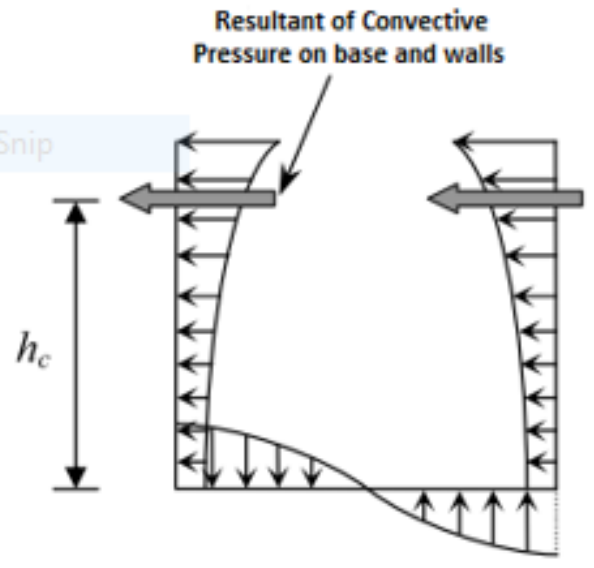

(b) Convective pressure on wall and base

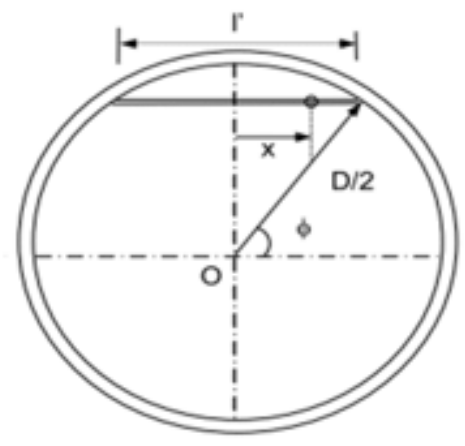

(d) Pressure in vertical direction of tank base

Figure 7 Hydrodynamic pressure distribution

The hydrodynamic pressure distribution is shown in Figure 7, The total hydrodynamic pressure of fluid exerted on the structure walls is compared with the guidelines for seismic design of liquid storage tanks, both impulsive and convective hydrodynamic pressure components are revealed by design codes depends upon the mode of oscillations (Sudhir and Jaiswal, 2007). Time period of impulsive response is given by Equation (10).

$T_{i}=C_{i} \frac{h \sqrt{\rho}}{\sqrt{t / D} \sqrt{E}}$

Time period of convective response is given by Equation (11)

$T_{c}=C_{c} \sqrt{\frac{D}{g}}$

Where $\mathrm{h}$ fluid fill height, $\rho$ fluid density $\mathrm{D}$ inner diameter of the tank, $\mathrm{t}$ is the thickness of the tank, and $\mathrm{E}$ is the modulus of elasticity of the material. Convective frequency depends upon the geometry of the tank with fluid depth while 
impulsive frequency also takes on board the elastic properties of the structure. while $C_{i}=f(h / D)$ is convective coefficients and $C_{c}=f(h / D)$ convective coefficients, Using the above equations Table 4 shows the result of impulsive time period frequency, and Table 5 shows the convective frequency independent of structure thickness parameter calculated from Equation (10) and Equation (11).

Table 4 Impulsive time period frequency

\begin{tabular}{cccc}
\hline & \multicolumn{3}{c}{ Impulsive Frequency Hz } \\
\hline Thickness $\mathbf{m m}$ & Fill Level 25\% & Fill Level 50\% & \\
\hline 5 & 12.71 & 6.91 & Fill Level 75\% \\
7.4 & 15.87 & 8.64 & 5.34 \\
11.1 & 18.93 & 10.31 & 6.26 \\
14.8 & 21.88 & 11.9 & 7.44 \\
\hline
\end{tabular}

Table 5 Convective time period frequency

\begin{tabular}{cccc}
\hline \multicolumn{4}{c}{ Convective Frequency Hz } \\
& Fill Level 50\% & Fill Level 75\% \\
\hline Frequency & 0.68 & 0.647 & 0.65 \\
\hline
\end{tabular}

Hydrodynamic pressure on tank wall due to vertical ground acceleration is given by Equation (12).

$$
P_{v}=A_{V}[\rho g h(1-y / h)]
$$

Where $\mathrm{y}$ is the vertical distance of a point on the tank wall from the base of the tank wall and $A_{v}$ vertical seismic coefficient.

Pressure on the wall due to its inertia is given by Equation (13).

$P_{w}=A_{h} t \rho_{m} g$

Where $\rho_{m}$ mass density of the tank wall and $A_{h}$ horizontal seismic coefficient.

Impulsive hydrodynamic pressure is given by Equation (14).

$P_{i}=0.866\left[1-\left(\frac{y}{h}\right)^{2}\right] \tanh \left(0.866 \frac{D}{h}\right)\left(A_{h}\right)_{i} \rho g h \cos \varnothing$

Convective hydrodynamic pressure is given by Equation (15).

$P_{c}=0.5625\left[\frac{\cosh \left(3.674^{y / D} / D\right)}{\cosh (3.674 h / D)}\right]\left(A_{h}\right)_{c} \rho g D\left[1-\frac{1}{3} \cos ^{2} \varnothing\right] \cos \varnothing$

Hence, Maximum hydrodynamic pressure is obtained by combining pressure due to vertical excitations from Equation (12) and horizontal excitation from Equations (13, 14 and15) through the square root of the sum of squares (SRSS) rule, and represented in Equation (16).

$P=\sqrt{\left(P_{i}+P_{w}\right)^{2}+P_{c}^{2}+P_{v}^{2}}$ 
Calculating the above equations analytical results are compared with numerical results. The differences observed in maximum values of pressure are less than $4.3 \%, 0.8 \%$, and $1.507 \%$ in three fluid fill level cases i.e $25 \%, 50 \%$, and $75 \%$ respectively as shown in Figure 8 represents the comparison of maximum hydrostatic pressure during seismic excitation.

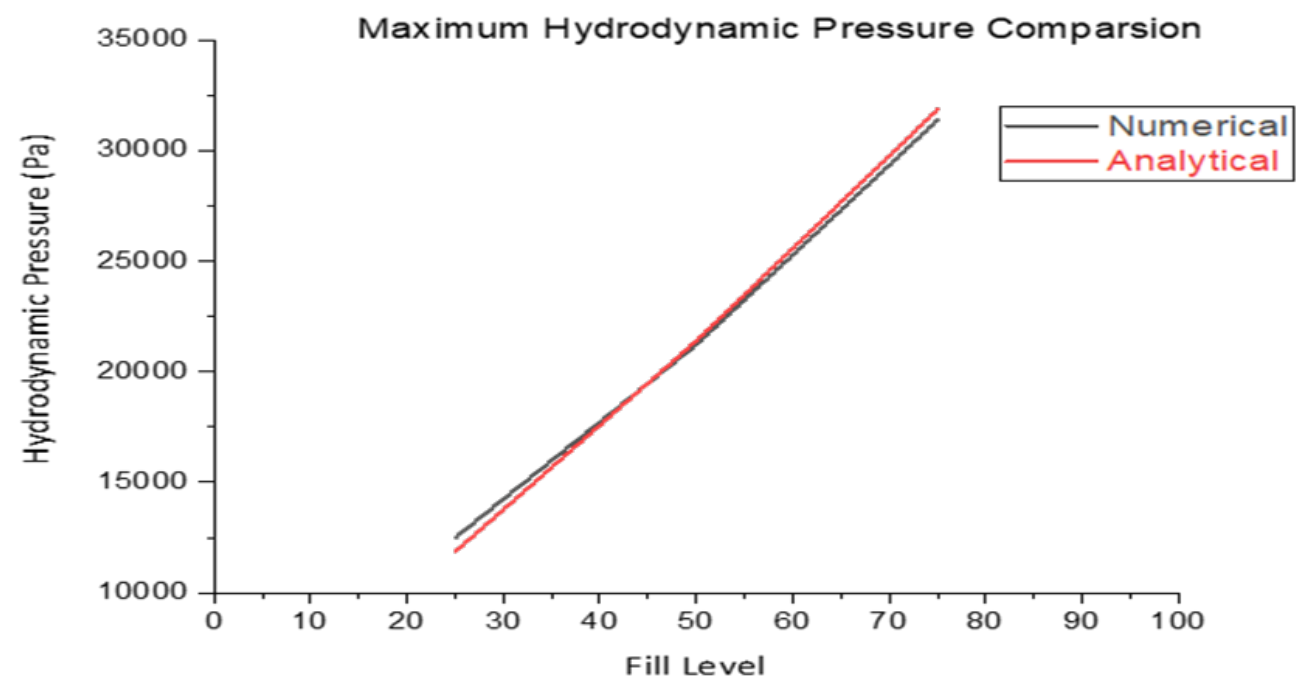

Figure 8 Comparison of maximum hydrodynamic pressure values

\subsection{Total Pressure}

The total pressure is the sum of the mechanical energy per unit volume in a fluid include static pressure, dynamic pressure, and the gravitational potential energy per unit volume. The seismic response is evaluated employing time history analysis, Therefore the time history of total pressure is the sum of the time histories of impulsive, convective, and flexible pressure (distribution on walls). Analytical and numerical time history of the total pressure is compared and variation is plotted at each time step having different variation with time and observed that the averaged difference is less than $0.4 \%$ which is under $90 \mathrm{~Pa}$, and the minimum and maximum total pressure difference are $-1.5268 \%$ and $+1.5758 \%$ at transient step 103 and step 130 respectively. Figure 9 represents the comparison of the transient time history of total pressure. Figure 10 general overview transient hydrodynamic pressure distribution due to sloshing under seismic excitation.

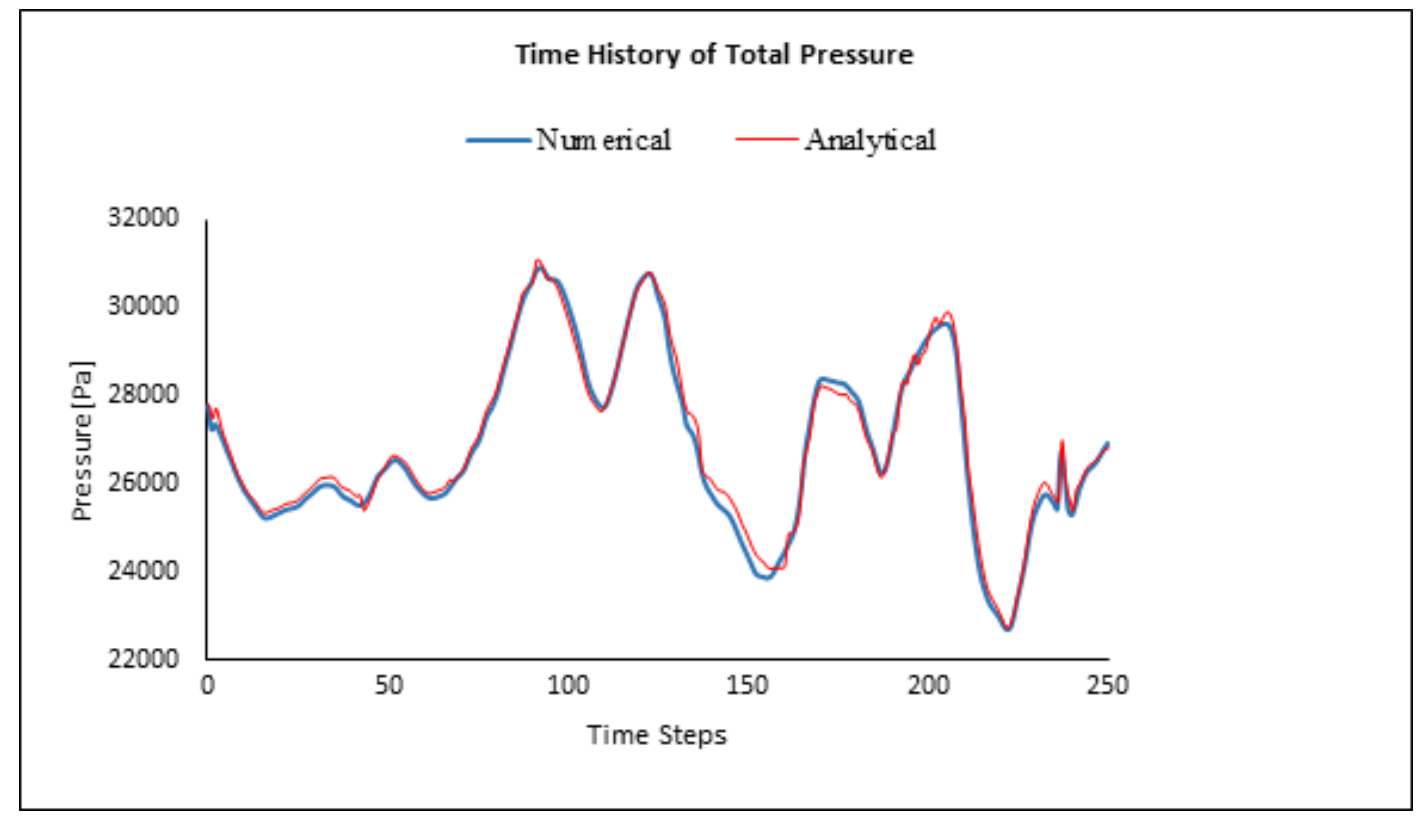

Figure 9 Comparison of the transient time history of total pressure 


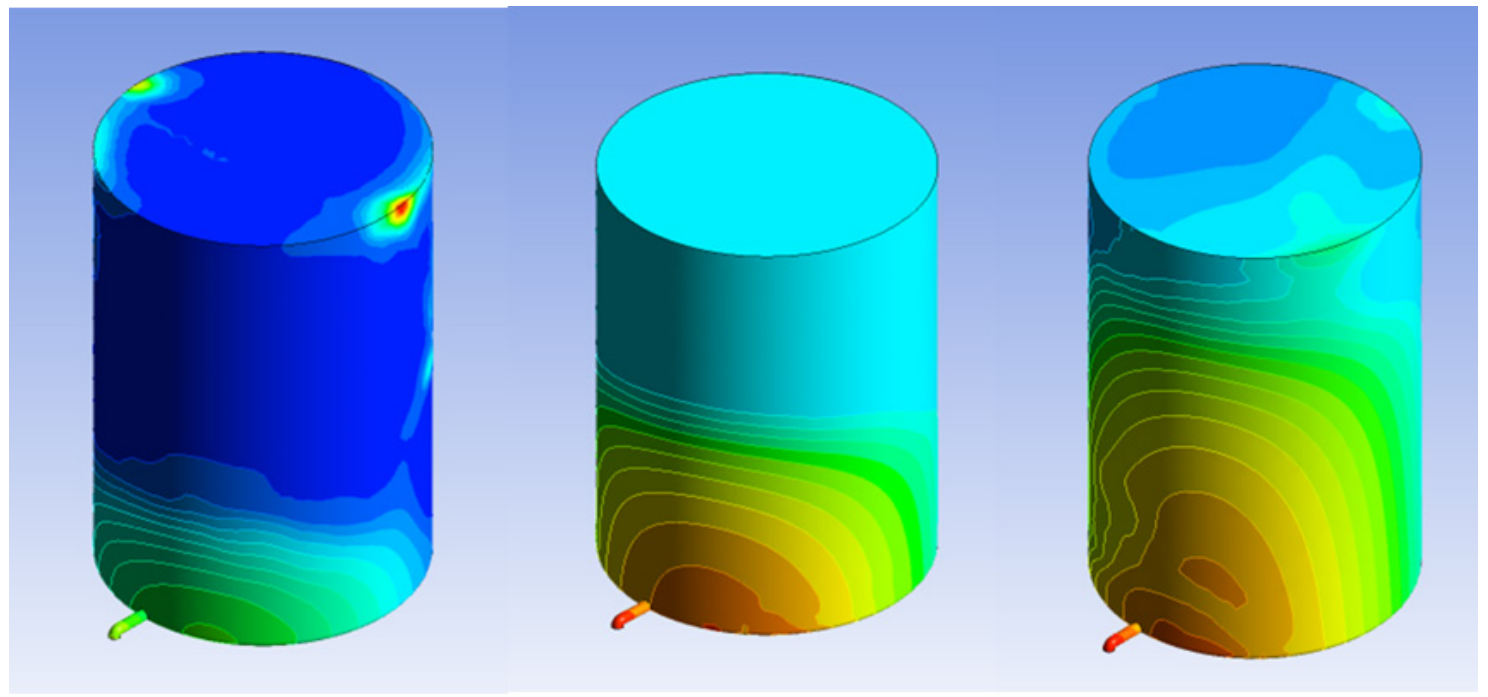

Figure 10 Transient pressure distribution during sloshing

\section{RESULTS AND DISCUSSIONS}

Time history analyses are performed to investigate the realistic response of the system and it is compared with design codes, and reliable safe design for three fill levels of fluid have been carried with anchored (fixed) and unanchored (flexible) acid storage tank with four different wall thickness coupled with a fixed piping system and results are plotted on 3D graphs in subsections to develop a reliable safe design methodology and relationship.

\subsection{Base uplift}

To provide appropriate flexibility in the design of any piping system coupled with the tank wall maximum base uplift is important. Factors affecting base uplift are fluid height, wall thickness, base moment, and force reaction.

Maximum base uplift is obtained in the fixed and flexible tank both having a fixed piping attachment, from Figure 11 uplift behavior is increased rapidly in the unanchored flexible tank as the fill level increases leading towards rapid breakage and bulging at a pipe joint as shown in Figure 12.

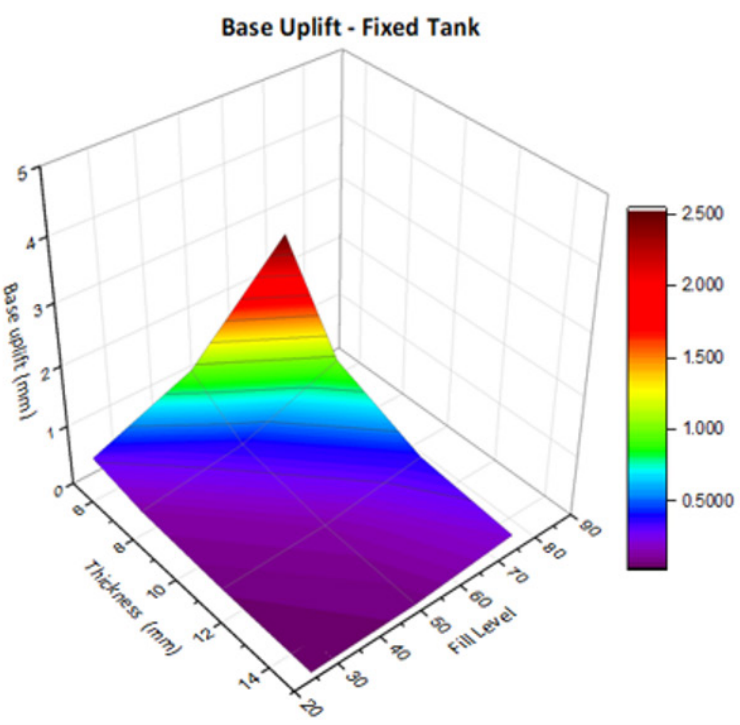

(a) Base uplift in fixed tank

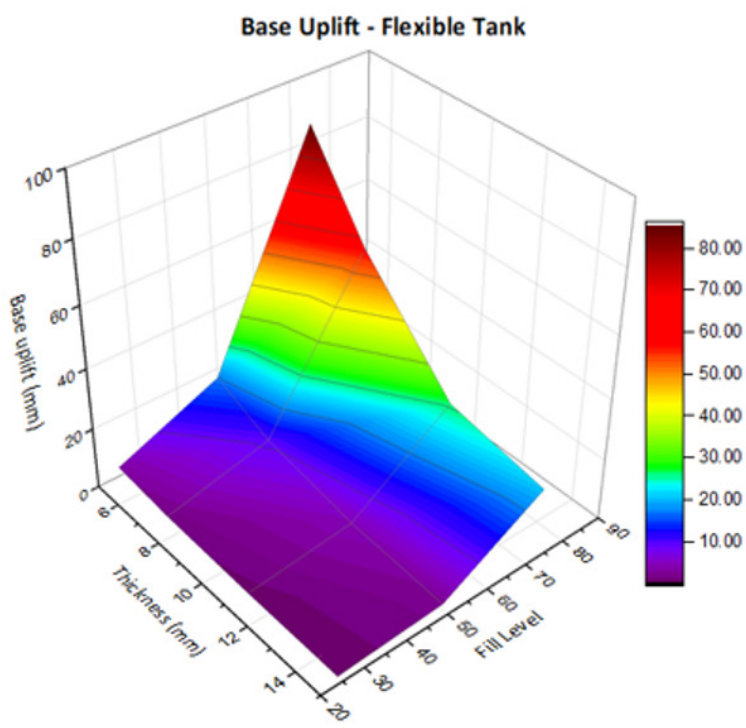

(b) Base uplift in flexible tank

Figure 11 Base uplifts 


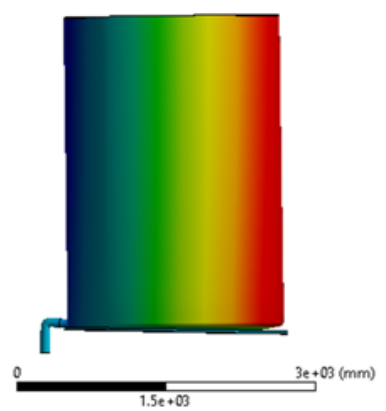

(a) base uplift opposite to pipe side

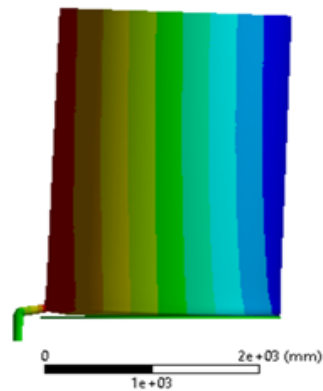

(b) base uplift and bulging pipe side

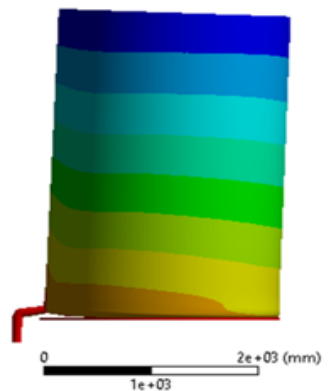

(C) base uplift and pipe breakup

Figure 12 Breakage and bulging due to base uplift

Other factors affecting base uplift are moment reaction and force reaction observed that fill level affects these factors more as compared to wall thickness. As displayed in Figure 13 moment reaction changes slightly in the thickness range while change drastically from $8.0 \times 10^{6} \mathrm{~N}-\mathrm{mm}$ to $4.5 \times 10^{7} \mathrm{~N}-\mathrm{mm}$ at a greater $\mathrm{H} / \mathrm{D}$ ratio of above 1 , Similarly Figure 14 displays Force reactions its value remains approximate same, negligible in the thickness range while double from $33 \mathrm{KN}$ to $66 \mathrm{KN}$ and $110 \mathrm{KN}$ at increased H/D ratio of $0.3645,0.73$ and 1.094 respectively.

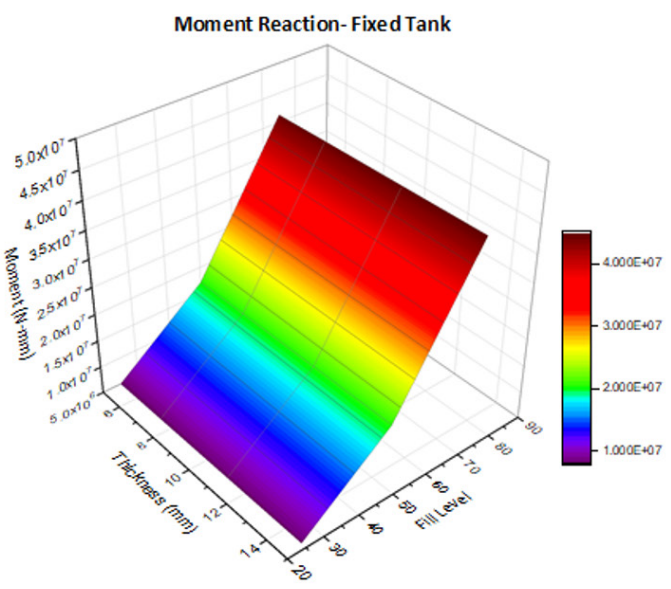

(a) Moment reaction of fixed tank

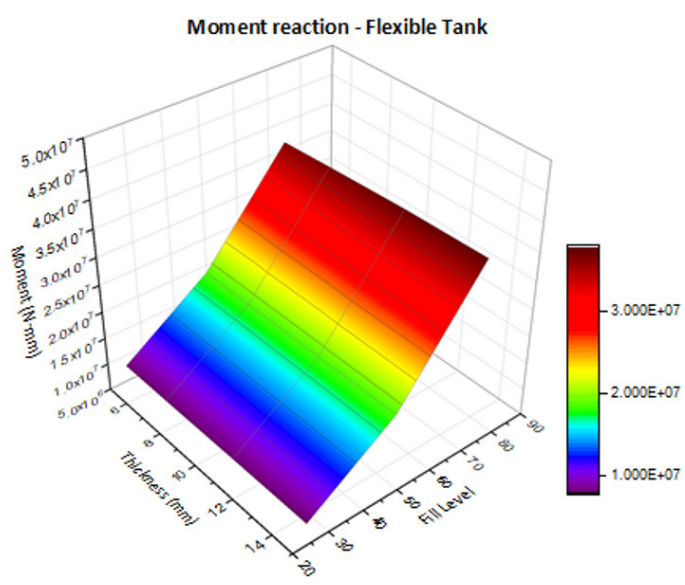

(b) Moment reaction of unanchored flexible tank

Figure 13 Moment reactions

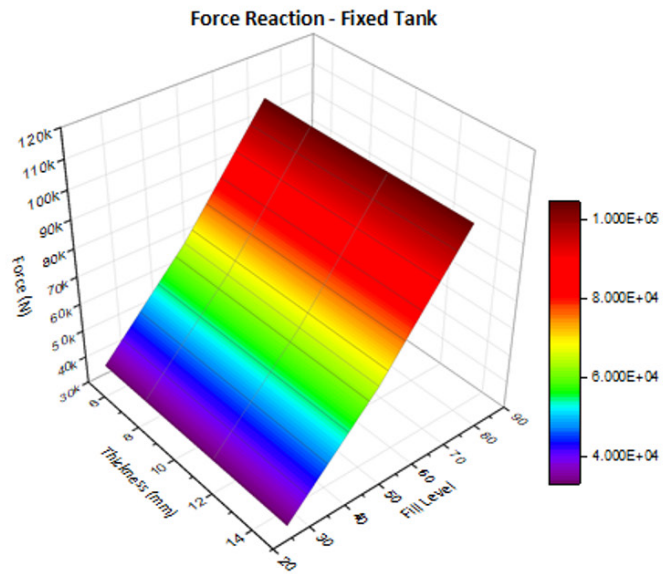

(a) Force reaction of fixed tank

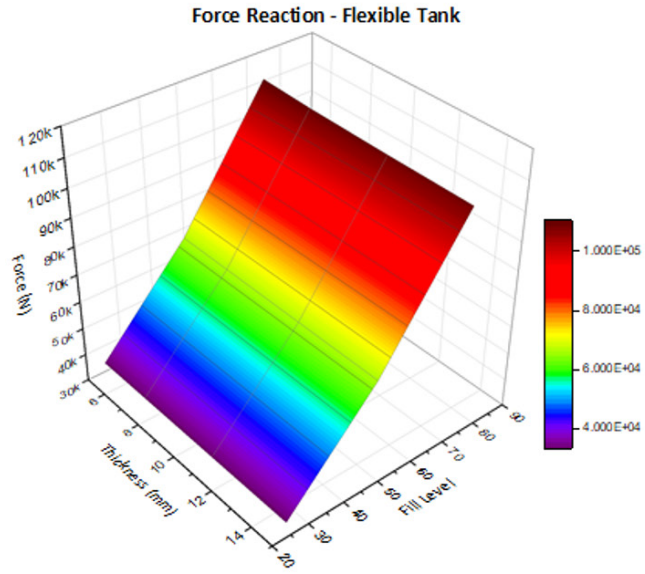

(b) Force reaction of unanchored flexible tank

Figure 14 Force reactions 


\subsection{Horizontal Deformations}

When the structure is under seismic load the response of deformation at different fill levels and thickness values effects are the result of fluid motion, the interaction of the fluid with a tank, and piping attachment. Horizontal deformations in east-west and north-south directions are a function of fluid fill levels and wall thickness. These are investigated individually both for the fixed and unanchored flexible structure. Figure 15 and Figure 16 displays 3D graphical deformation along north-south and along with east-west directions respectively.

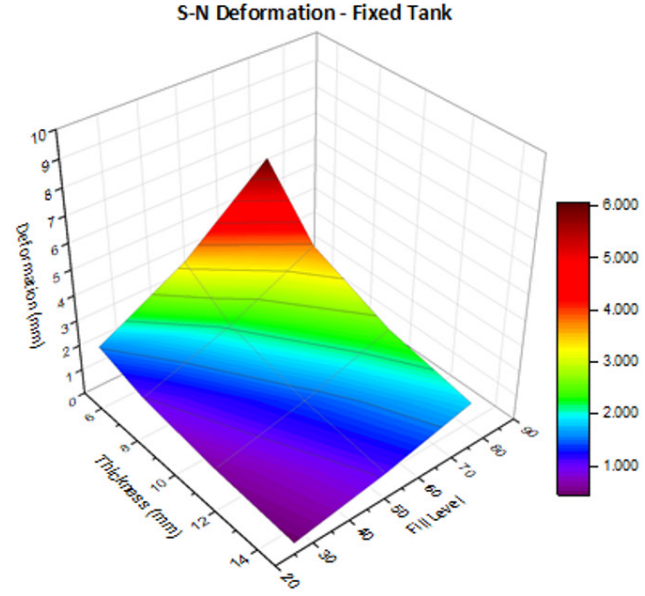

(a) Directional deformation north-south in anchored tank

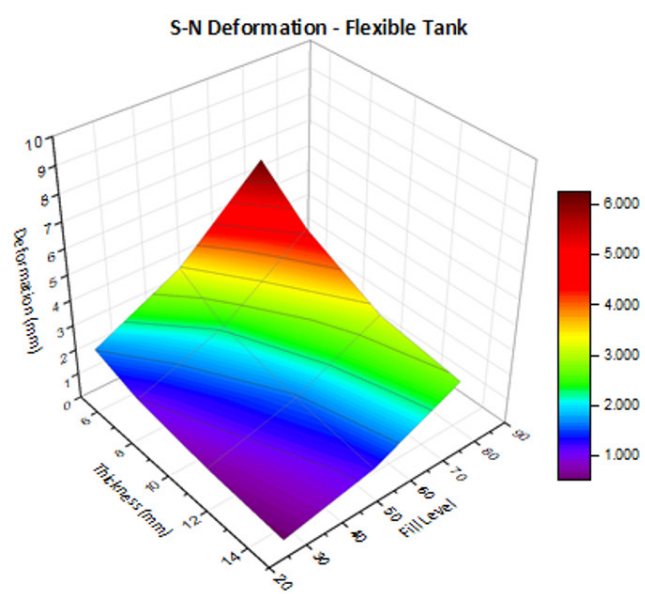

(b) Directional deformation north-south in unanchored tank

Figure 15 Directional deformation along north-south direction

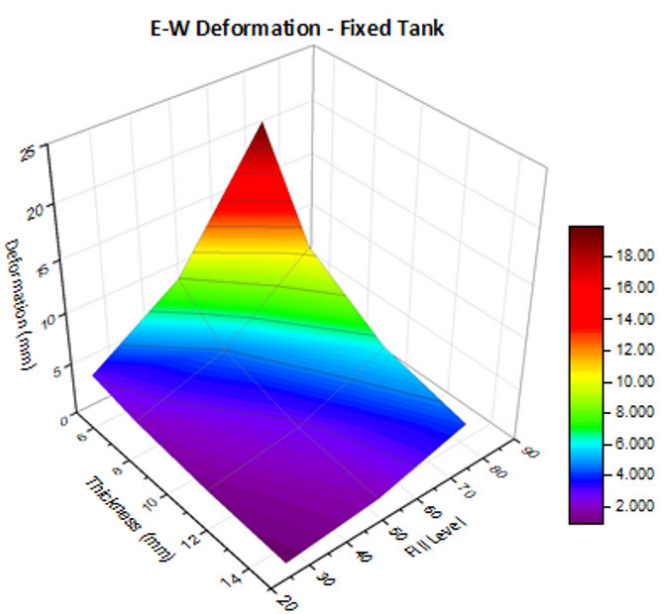

(a) Directional deformation east-west in anchored tank

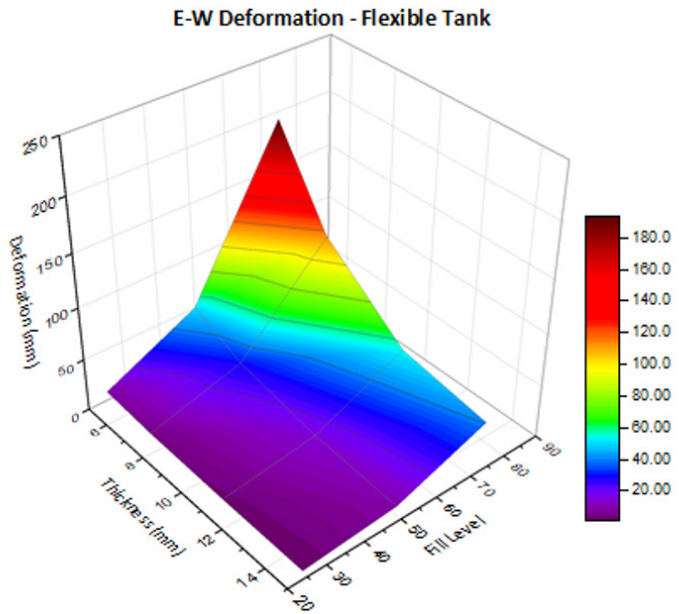

(b) Directional deformation east-west in unanchored tank

Figure 16 Directional deformation along east-west direction

The directional deformation trend indicated that a maximum response in the east-west direction with a peak ground acceleration (PGA) of $0.361 \mathrm{~g}$, both for anchored and unanchored structures follow the same trend. That is deformation decreases by lowering fluid fill level and increasing wall thickness, it is observed that for an unanchored system the response is more vulnerable in the range of $H / D$ ratio above 1 , with wall thickness half the design thickness and this is sufficient enough to damage the piping attachment. Optimized fluid fill levels are in the range of H/D ratio below 1 , with a wall thickness in the range of $50 \%$ to $75 \%$ of design thickness obtained using the standard code formula.

\subsection{Stress and Strain Response}

The stress distribution on the structure is influence by the fluid sloshing pressure under seismic loading at various fluid fill levels, Figure 17 displays the FSI pressure distribution inside the tank walls. For the safety of structure stress is 
the main factor, therefore to evaluate the safety of structure stress distribution should be investigated subjected to earthquakes.
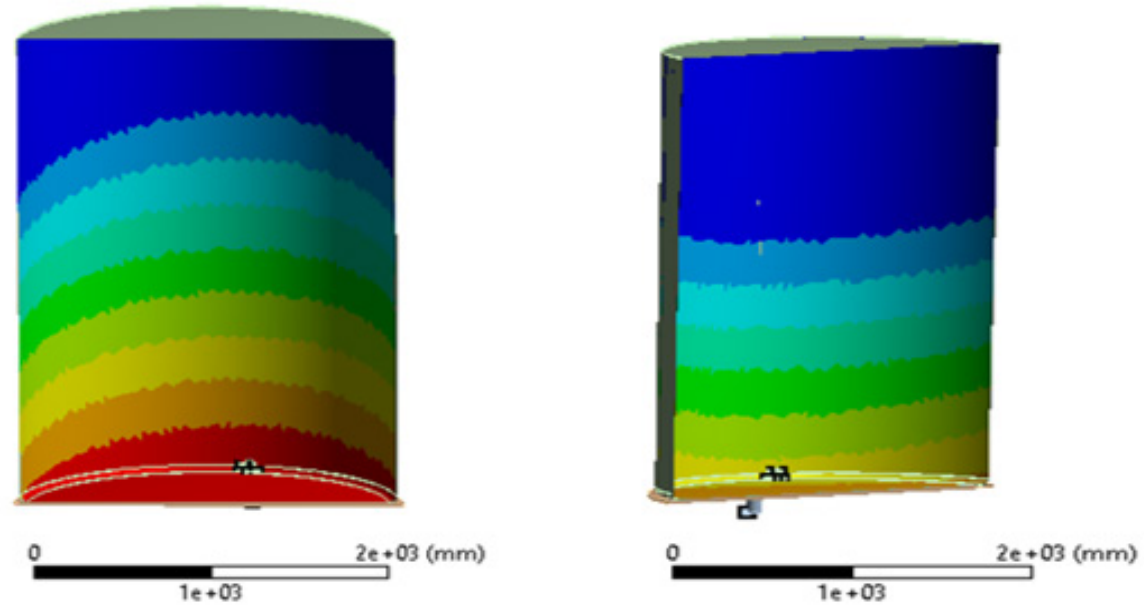

Figure $17 \mathrm{FSI}$ pressure distribution inside the tank walls

The stresses are strongly influenced by the fluid fill level and the maximum stresses are largest at the edges, pipe joints, and elbow as shown in Figure 18, which are the most vulnerable points for stresses and strains. Therefore, these are the weakest location under seismic excitations for various fluid levels, the maximum stress distribution in both anchored and the unanchored case is located on piping attachment with the tank.

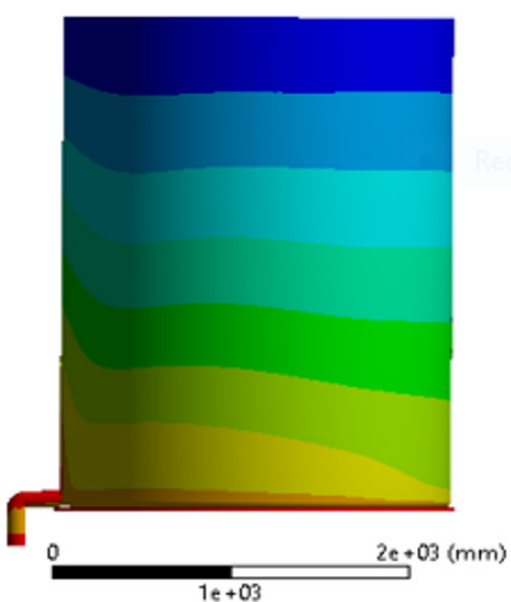

(a) Stress vulnerable points

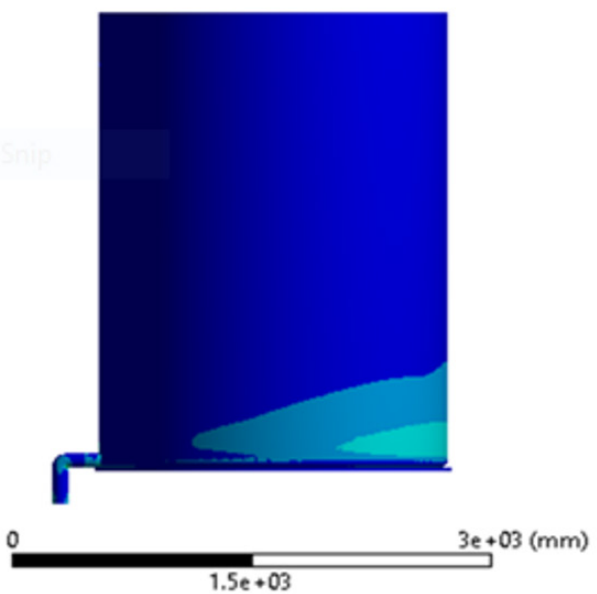

(b) Strain Vulnerable points

Figure 18 Vulnerable points affected by stress and strain

The maximum stress and strain due to change in the fluid fill level with considering wall thickness under seismic excitation are investigated and represented in Figure 19 for the anchored and unanchored tank with piping attachments. Greater stresses when wall thickness below the $1 / 2$ of calculated design thickness causing damage and bulging the pipe joint, with thickness in the range of $1 / 2$ to $3 / 4$ of design thickness structure can be catered by providing anchorage and sufficient strength to vulnerable points, while thickness greater $3 / 4$ of the design calculated thickness maximum stresses are below $50 \mathrm{MPa}$ in both cases of anchored and unanchored under different fluid levels and is safe. Thus, it is needed to consolidate the edges, pipe joints and elbows to ensures structure safety. 


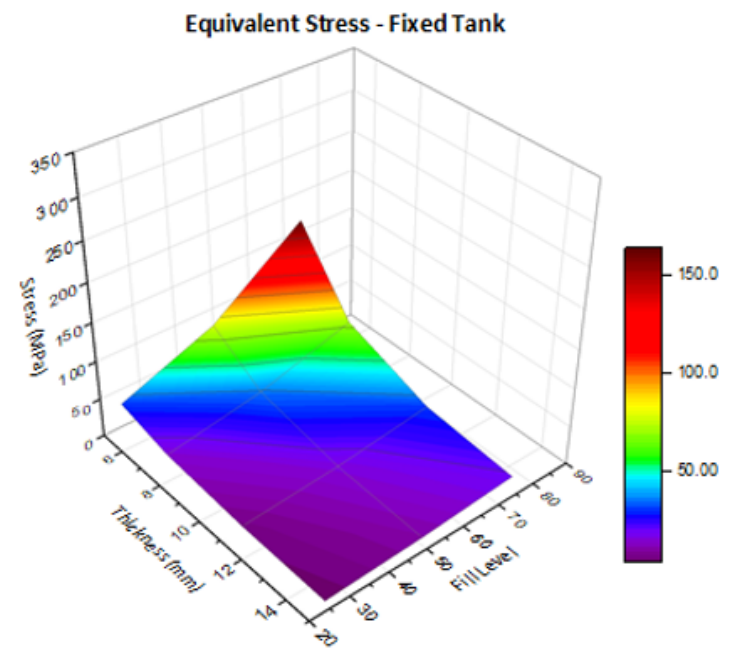

(a) Equivalent Stress in anchored tank

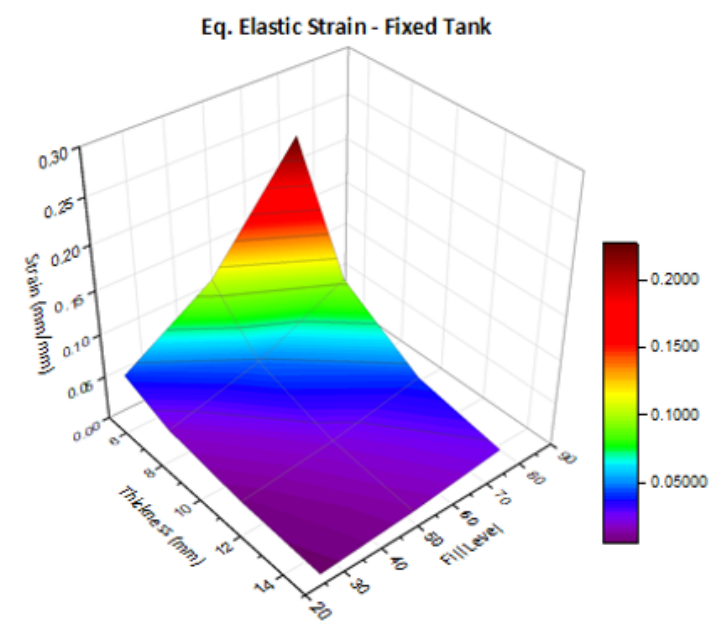

(c) Equivalent elastic strain in anchored tank

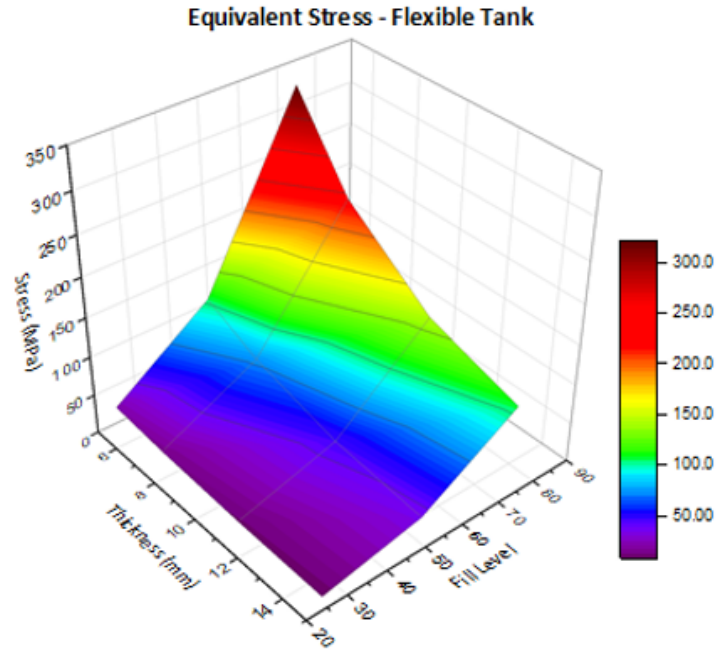

(b) Equivalent Stress in unanchored tank

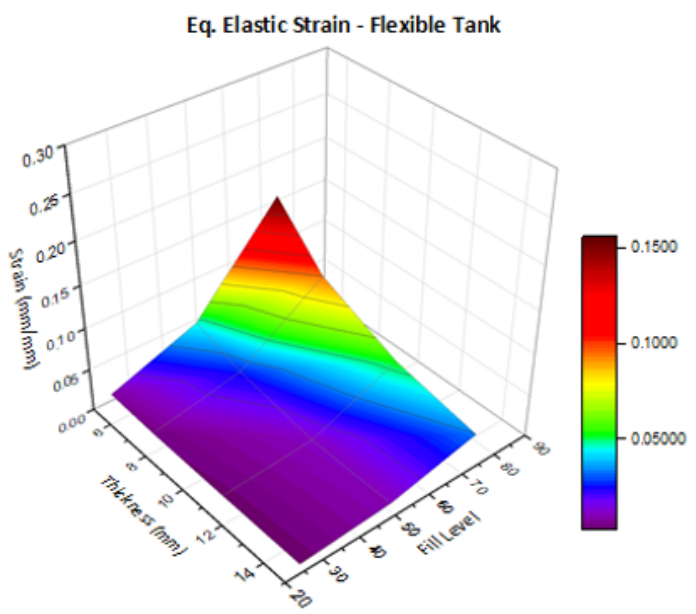

(d) Equivalent elastic strain in unanchored tank

Figure 19 Equivalent stresses and Equivalent Elastic Strains

\section{EMPIRICAL CORRELATION}

From the above results, it is obvious that a nonlinear empirical relationship of second order polynomial as expressed in Equation (17) may represent the response. Hence

$Z=z_{0}+a t+b f+c t^{2}+d f^{2}+e t f$

Where $t$ is thickness, $f$ is filled level and $Z$ is parameter under consideration (uplift, reaction moment, reaction force, $E$ $\mathrm{W}$ deformation, N-S deformation, stress, and strain), Where $\mathrm{z}_{0}, \mathrm{a}, \mathrm{b}, \mathrm{c}, \mathrm{d}$, and e are constant.

Figure 20 and Figure 21 that the fitting accuracy $R^{2}$ of the proposed surface represented by the above relation is equal to 1 (>0.9999) in all cases and similarly Reduced chi square values are also in the acceptable range. Therefore, the relationship is the proposed empirical relation. 


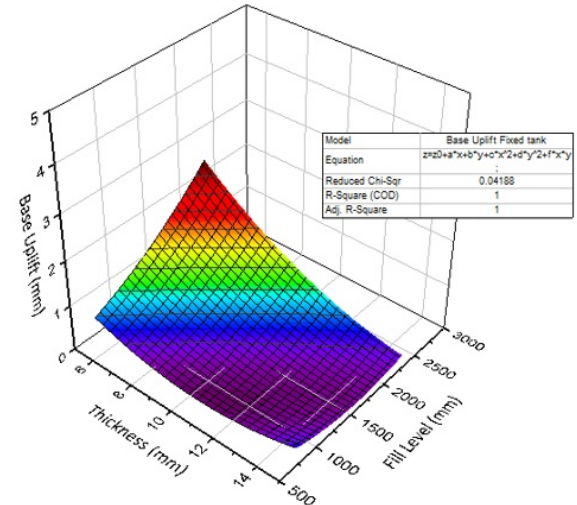

(a) Base uplift

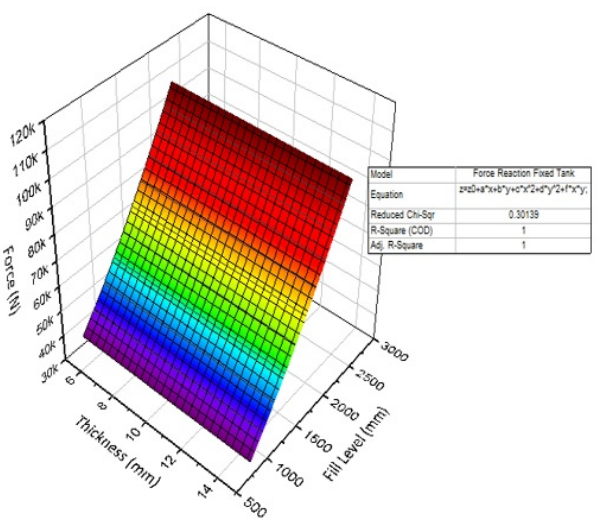

(c) Force Reactions

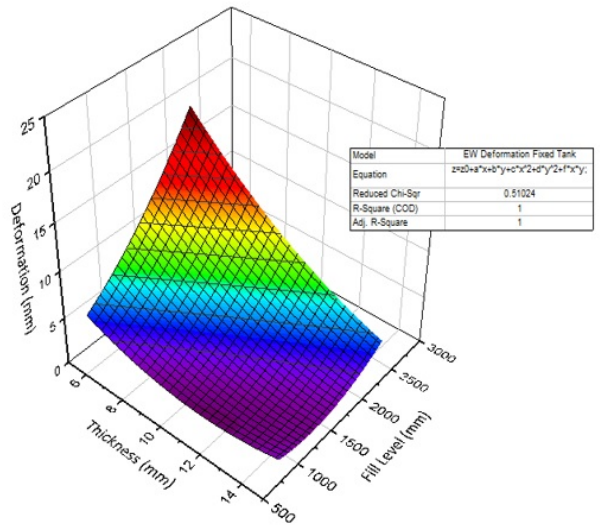

(e) E-W Deformation

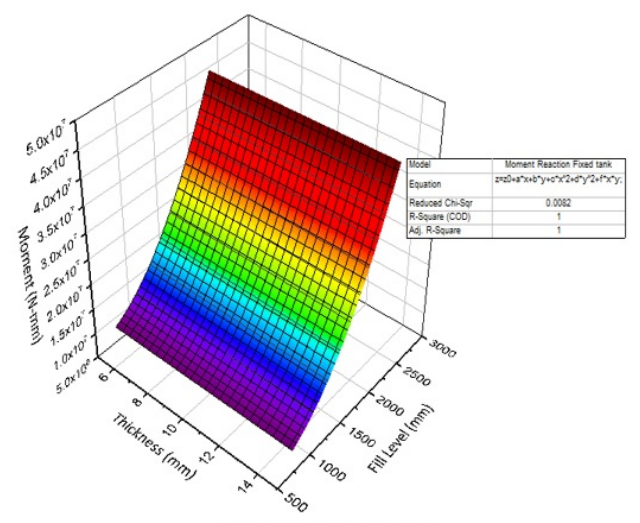

(b) Moment Reactions

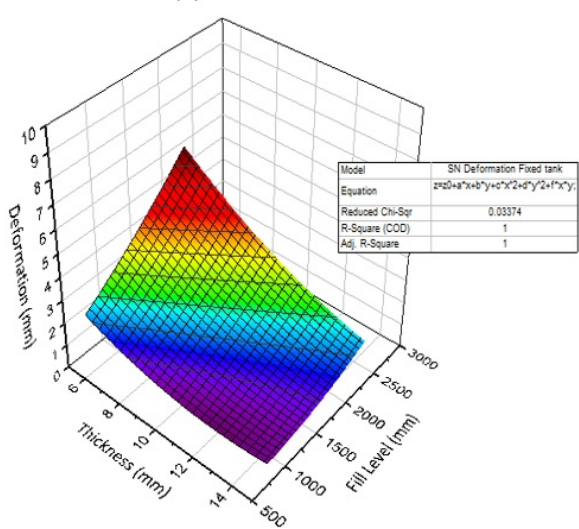

(d) N-S Deformation

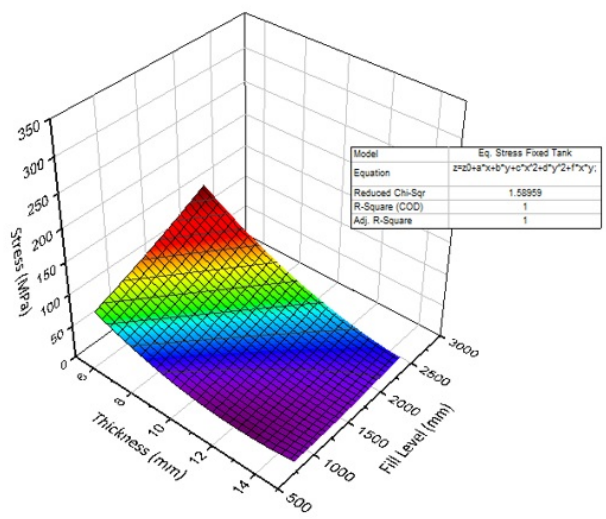

(f) Eq. Stress

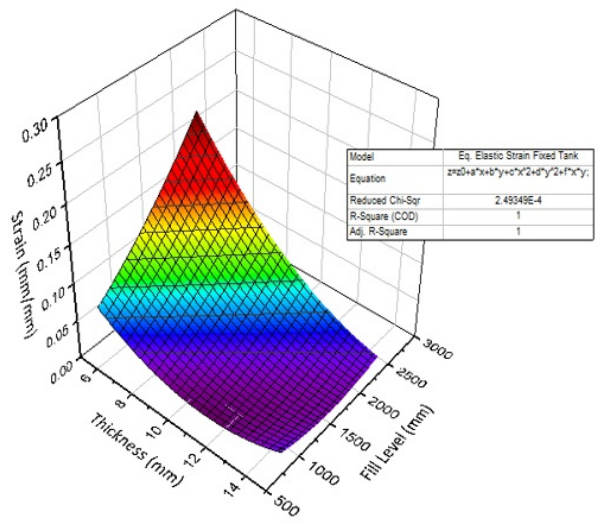

(g) Eq. Elastic Strain

Figure $\mathbf{2 0}$ Nonlinear relationship of the fixed tank model 
Table 6 Values of fixed tank parameters

\begin{tabular}{ccccccccc}
\hline & $\mathbf{Z}_{\mathbf{0}}$ & $\mathbf{a}$ & $\mathbf{b}$ & $\mathbf{c}$ & $\mathbf{d}$ & e & $\mathbf{R}^{2}$ & Red Chi Sqr \\
\hline Uplift & 0.73808 & -0.22694 & 0.0008756 & 0.0159 & $3.04267 \mathrm{E}-07$ & -0.0001286 & 1 & 0.04188 \\
Moment & $8.05 \mathrm{E}+06$ & -12646.474 & -7622.9306 & 259.77759 & 9.69689 & 23.89562 & 1 & 0.0082 \\
Force Reaction & 8335.6844 & -4.70203 & 27.05483 & 1.10846 & 0.00584 & -0.02728 & 1 & 0.30139 \\
E-W Deformation & 3.74098 & -1.00125 & 0.00596 & 0.0729 & $2.23 \mathrm{E}-06$ & -0.000788 & 1 & 0.51024 \\
N-S Deformation & 1.64501 & -0.38865 & 0.0025 & 0.022 & $3.41656 \mathrm{E}-07$ & -0.0001939 & 1 & 0.03374 \\
Stress & 86.12559 & -18.29758 & 0.05835 & 0.89733 & $5.30257 \mathrm{E}-06$ & -0.00459 & 1 & 1.58959 \\
Strain & 0.07711 & -0.02238 & $9.749 \mathrm{E}-05$ & 0.00142 & $1.82 \mathrm{E}-08$ & $-1.06 \mathrm{E}-05$ & 1 & 0.00024935 \\
\hline
\end{tabular}

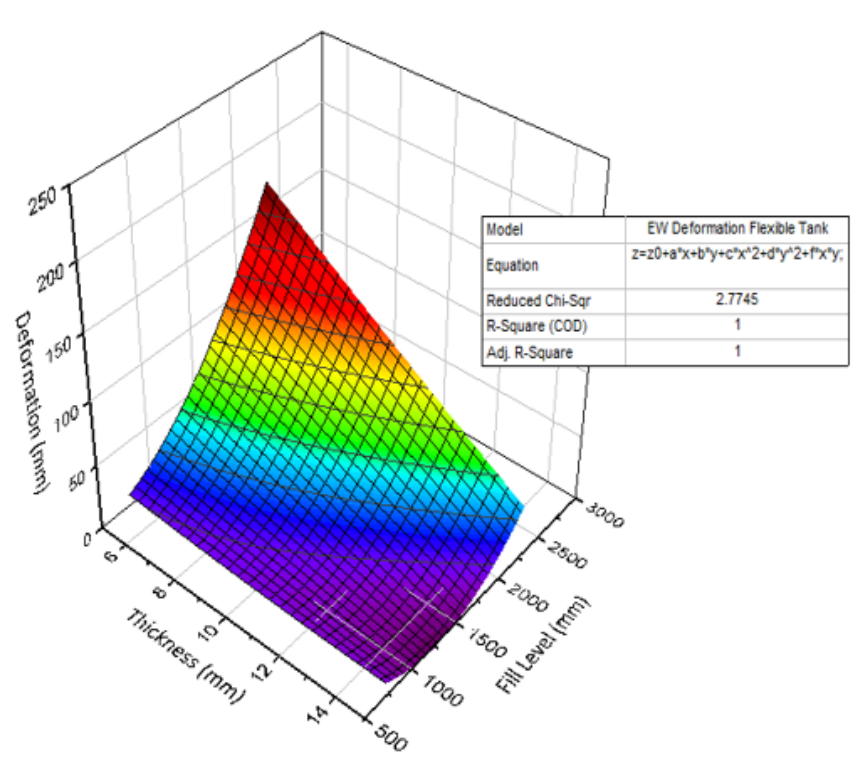

(e) E-W Deformation

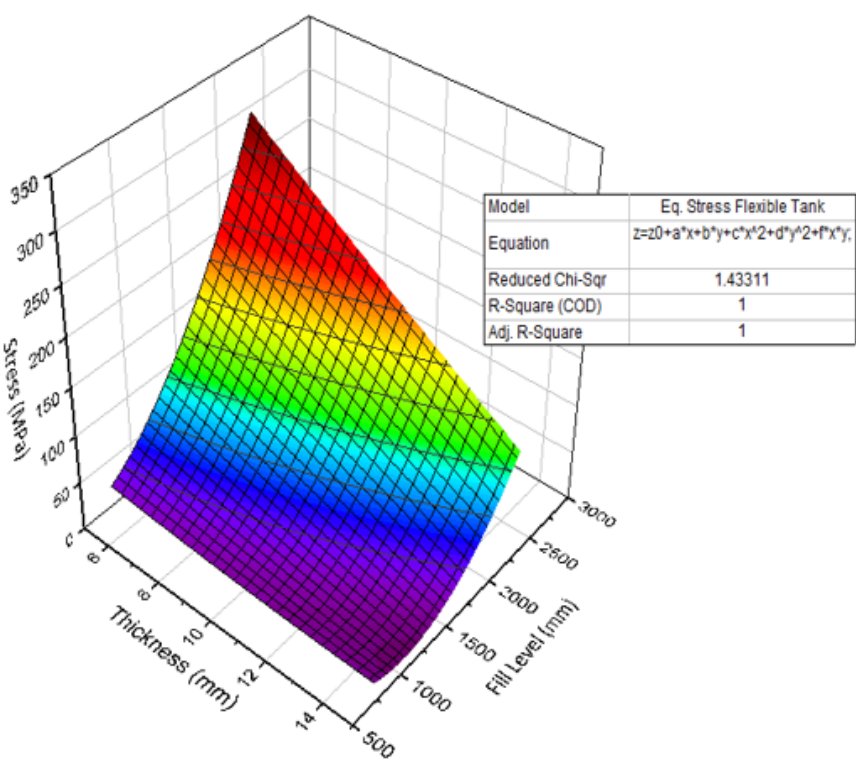

(f) Eq. Stress

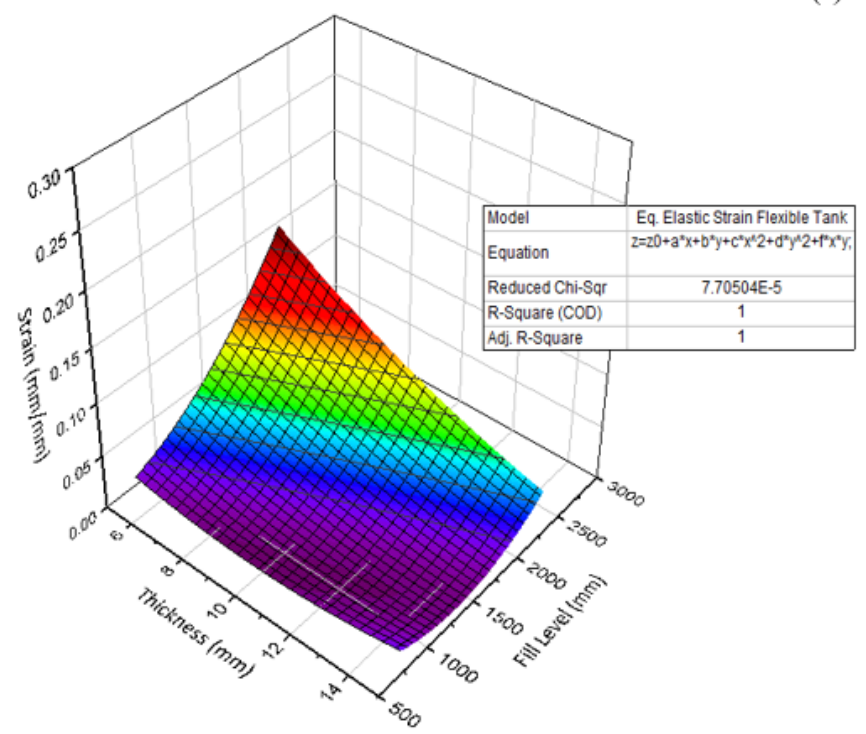

(g) Eq. Elastic Strain

Figure 21 Nonlinear relationship of Unanchored flexible tank model 
Table 7 Values of unanchored flexible tank parameters

\begin{tabular}{ccccccccc}
\hline & $\mathbf{Z}_{\mathbf{0}}$ & $\mathbf{a}$ & $\mathbf{b}$ & $\mathbf{c}$ & $\mathbf{d}$ & $\mathbf{f}$ & $\mathbf{R}^{2}$ & $\mathbf{R e d ~ C h i ~ S q r}$ \\
\hline Uplift & 27.40906 & -5.93562 & 0.00198 & 0.44316 & $1.93 \mathrm{E}-05$ & -0.00368 & 1 & 2.8171 \\
Moment & $5.97 \mathrm{E}+06$ & -70033.9 & -2430.87 & -446.529 & 6.3714 & 89.8277 & 1 & 8.066 \\
Force Reaction & 10089.41 & 35.47274 & 23.03452 & 1.22672 & 0.00834 & -0.08085 & 1 & 3.3799 \\
E-W Deformation & -22.1566 & 4.50619 & 0.01905 & 0.07661 & $3.98 \mathrm{E}-05$ & -0.00851 & 1 & 2.7745 \\
N-S Deformation & 2.10642 & -0.32204 & 0.00117 & 0.01693 & $7.73653 \mathrm{E}-07$ & -0.00016 & 1 & 0.0208 \\
Stress & -28.0122 & 5.54549 & 0.03093 & 0.11792 & $6.37 \mathrm{E}-05$ & -0.01158 & 1 & 1.433 \\
Strain & 0.00487 & -0.00306 & $1.94 \mathrm{E}-05$ & $4.83 \mathrm{E}-04$ & $3.38 \mathrm{E}-08$ & $-7.65 \mathrm{E}-06$ & 1 & 0.000077 \\
\hline
\end{tabular}

The converged results with fitting accuracy $\mathrm{R}^{2}$ of nonlinear fitting of both anchored and unanchored structure with parameters values for expressing second order polynomial are tabulated in Table 6 and Table 7. These equations are compared at different points with results values to average out the difference and accuracy between the analysis results and with the surface fitting equation. The average difference for both cases is tabulated in table 8 .

Table 8 Percentage average difference

\begin{tabular}{|c|c|c|c|c|c|c|}
\hline & Moment & Force Reaction & E-W Deformation & N-S Deformation & Stress & Strain \\
\hline Fixed Tank & $2.786 \%$ & $1.701 \%$ & $4.13 \%$ & $4.51 \%$ & $4.64 \%$ & $6.5 \%$ \\
\hline Flexible Tank & $2.4924 \%$ & $1.772 \%$ & $1.53 \%$ & $1.783 \%$ & $0.043 \%$ & $0.101 \%$ \\
\hline
\end{tabular}

The overall average difference in the unanchored flexible tank is less than $2 \%$ while in the fixed tank near to $5 \%$ with proposed empirical relation and results from values Therefore, the above developed relationship can be well expressed in Equation (17).

\section{CONCLUSIONS}

The overall purpose of this study focuses on safe design improvement through numerically investigation and simulation of the FSI effects of hydrodynamics on acid storage tank with piping attachment by using the ANSYS workbench and develop a methodology relationship by adopting 3D nonlinear fitting techniques. For a more realistic investigation full-scale response acceleration time history of Kocaeli earthquake magnitude 7.4, having maximum eastwest PGA of $0.361 \mathrm{~g}$, south-north PGA of $0.310 \mathrm{~g}$, and vertical PGA of $0.205 \mathrm{~g}$ is performed on a full 3D system model (fluid and structure). Time history analysis is closer to accuracy as numerical results are validated and compare with analytical results by using design codes. The difference observed in hydrostatic pressure is less than $0.08 \%$, the average difference in hydrodynamic pressure, the differences observed in maximum values of hydrodynamic pressure are less than $4.3 \%, 0.8 \%$, and $1.507 \%$ at three fluid fill level while the average difference in transient time history total pressure is less than $0.4 \%$.

For purpose of safe design which has the least seismic response simulations are performed on three fluid fill levels at $H / D$ of $0.6347,0.73$, and 1.094 with the combination of different wall thickness ranging from minimum 5 mm to a maximum of $14.8 \mathrm{~mm}$ both for the rigidly anchored fixed and unanchored flexible full-scale model. Critical parameters like base uplift, directional deformations, and maximum stress and strain are considered for improved safe design, and the observations are as follow,

1. Base uplift is reduced at low fluid fill heights both in anchored and unanchored tanks, for the anchored tank and piping system contribution of the base uplift due to the hydrodynamic action is usually small, but the behavior increased rapidly in the unanchored tank as the fill level increases leading towards rapid breakage and bulging at a pipe joint, for the anchored tank at wall thickness half the design, maximum base uplift is below $1 \mathrm{~mm}$ while for unanchored fill level H/D = 1 tank at a wall thickness of three fourth of design thickness maximum base uplift is below $5 \mathrm{~mm}$ and it can be reduced by providing anchorage.

2. Design is safe due to Horizontal deformations at fluid fill levels in the range of H/D ratio below 1 , with a wall thickness of half to three fourth of design thickness obtained using standard code by the formula.

3. Larger stresses are observed when the wall thickness is below half of the design thickness and it causes damaging and bulging the pipe joint, with thickness in the range of half to three fourth of design thickness structure can be 
catered by providing anchorage fixed supports and sufficient strength to vulnerable points, while thickness greater to three fourth of the design calculated thickness maximum stresses are below $50 \mathrm{MPa}$ in both cases of anchored and unanchored under different fluid fill levels structure is safe.

4. $\quad 2^{\text {nd }}$ order two dimensional polynomial correlation is developed for the model by using Nonlinear surface fitting model using Orthogonal Distance Regression with fitting accuracy of above 0.9999 the overall average difference is less than $5 \%$ in fixed tank and less than $2 \%$ in flexible tank.

Author's Contributions: Conceptualization, AJ Joya and MJ Hyder; Methodology, Investigation AJ Joya and Y Zulfiqar; Formal analysis, AJ Joya; Validation, AJ Joya, MJ Hyder and Y Zulfiqar; Writing - original draft, AJ Joya; Writing - review \& editing, AJ Joya and MJ Hyder.

Editor: Pablo Andrés Muñoz Rojas

\section{References}

ANSYS Inc. (2013) Workbench User's Guide, ANSYS Manual. Available at: http://148.204.81.206/Ansys/readme.html.

ASME (2003) ‘ASME B16.5 - 2003 Pipe Flanges and Flanged Fittings Metric / Inch Standard’, 2003.

Bursi, O. S. et al. (2015) 'Dynamic Response of Coupled Tanks and Piping Systems Under Seismic Loading', in Proceedings of the ASME 2015 Pressure Vessels \& Piping Conference PVP2015 July 19-23, 2015, Boston, Massachusetts, USA PVP2015-45131, p. V008T08A022. doi: 10.1115/pvp2015-45131.

Bursi, O. S., Reza, M. S. and Kumar, A. (2012) 'Seismic Performance of Bolted Flange Joints in Piping Systems for Oil and Gas Industries', in 15th World Conference on Earthquake Engineering, Lisbon Portugal.

Canonsburg, T. D. (2011) 'ANSYS CFX-Pre User's Guide', 15317(November), pp. 724-746.

Çelik, A. í. et al. (2018) 'Directional deformation analysis of cylindrical steel water tanks subjected to EL-Centro earthquake loading', Sigma J Eng \& Nat Sci, 36(4), pp. 1033-1046.

Chen, Y. G., Djidjeli, K. and Price, W. G. (2009) 'Numerical simulation of liquid sloshing phenomena in partially filled containers', Computers and Fluids, 38(4), pp. 830-842. doi: 10.1016/j.compfluid.2008.09.003.

Cherif, S. M. H. and Ouissi, M. N. (2016) 'Free vibration analysis of a liquid in a circular cylindrical rigid tank using the hierarchical finite element method', Latin American Journal of Solids and Structures, 13(7), pp. 1265-1280. doi: 10.1590/167978251774.

D1998 - 15 (2015) ‘Polyethylene Upright Storage Tanks', ASTM Standards. doi: 10.1520/D1998-15.

Eswaran, M. and Saha, U. K. (2013) 'Sloshing of liquids in partially filled tanks - a review of experimental investigations', Ocean Systems Engineering, 1(2), pp. 131-155. doi: 10.12989/ose.2011.1.2.131.

Ghazvini, T. et al. (2013) 'Seismic response of aboveground steel storage tanks: Comparative study of analyses by six and three correlated earthquake components', Latin American Journal of Solids and Structures, 10(6), pp. 1155-1176. doi: $10.1590 /$ S1679-78252013000600005.

Housner, B. G. W. (1963) 'The dynamic behavior of water tanks by george w. housner', bulletin of the Seismological Society of America, 53(2), pp. 381-387.

Jhung, M. J. and Ryu, Y. H. (2010) 'Study on Dynamic Response of Mechanical Component to Earthquake', Journal of Nuclear Science and Technology, 47(11), pp. 1065-1074. doi: 10.1080/18811248.2010.9711671.

Kochevsky, A. (2004) Possibilities of Simulation of Fluid Flows Using the Modern Cfd Software Tools, arXiv preprint physics/0409104. Available at: http://arxiv.org/abs/physics/0409104.

Krausmann, E., Cruz, A. M. and Affeltranger, B. (2010) 'The impact of the 12 May 2008 Wenchuan earthquake on industrial facilities', Journal of Loss Prevention in the Process Industries, 23(2), pp. 242-248. doi: 10.1016/j.jlp.2009.10.004. 
Malhotra, P. K., Wenk, T. and Wieland, M. (2000) 'Simple procedure for seismic analysis of liquid-storage tanks', Structural Engineering International: Journal of the International Association for Bridge and Structural Engineering (IABSE), 10(3), pp. 197-201. doi: 10.2749/101686600780481509.

Nicolici, S. and Bilegan, R. M. (2013) 'Fluid structure interaction modeling of liquid sloshing phenomena in flexible tanks', Nuclear Engineering and Design, 258, pp. 51-56. doi: 10.1016/j.nucengdes.2012.12.024.

De Oliveira França Júniora, D., Ribeirob, P. M. V. and Pedrosoa, L. J. (2019) 'Simplified expressions for dynamic behavior of cylindrical shells uncoupled and coupled with liquids', Latin American Journal of Solids and Structures, 16(6), pp. 1-19. doi: 10.1590/1679-78255546.

Sezen, H. and Whittaker, A. S. (2004) 'Performance of Industrial Facilities During the 1999, Kocaeli, Turkey Earthquake', in 13th World Conference on Earthquake Engineering, Vancuver, B.C, Canada.

Sudhir, K. J. and Jaiswal, O. R. (2007) Guidelines for Seismic Design of Liquid Storage Tanks, Report No. IITK-GSDMA-EQ08.

Surh, H. B. et al. (2015) 'Seismic response analysis of a piping system subjected to multiple support excitations in a base isolated NPP building', Nuclear Engineering and Design, 292, pp. 283-295. doi: 10.1016/j.nucengdes.2015.06.013.

Tahmasebi, M. K., Shamsoddini, R. and Abolpour, B. (2020) 'Performances of Different Turbulence Models for Simulating Shallow Water Sloshing in Rectangular Tank', Journal of Marine Science and Application, 19(3), pp. 381-387. doi: 10.1007/s11804-020-00162-2.

Tehranizadeh, Mohsen \& Amirmojahedi, Maryam \& Moshref, A. (2016) 'Simplified methods for seismic assessment of existing buildings', Earthquakes and Structures, 10(6), pp. 1405-1428. Available at: https://doi.org/10.12989/eas.2016.10.6.1405.

Zhao, M. \& Zhou, J. . (2018) 'Review of seismic studies of liquid storage tanks', Structural Engineering and Mechanics, 65(5), pp. 557-572. Available at: https://doi.org/10.12989/sem.2018.65.5.557. 